\title{
Methodological Characteristics, Physiological and Physical Effects, and Future Directions for Combined Training in Soccer: A Systematic Review
}

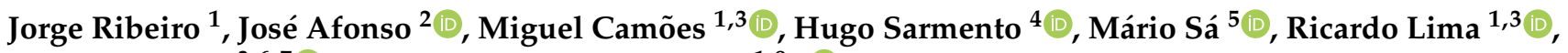 \\ Rafael Oliveira ${ }^{3,6,7}$ (1) and Filipe Manuel Clemente ${ }^{1,8, *(1)}$
}

1 Escola Superior Desporto e Lazer, Instituto Politécnico de Viana do Castelo, Rua Escola Industrial e Comercial de Nun'Álvares, 4900-347 Viana do Castelo, Portugal; jorgefaribeiro@hotmail.com (J.R.); joaocamoes@esdl.ipvc.pt (M.C.); ricardo.lima@esdl.ipvc.pt (R.L.)

2 Centre for Research, Education, Innovation and Intervention in Sport, Faculty of Sport of the University of Porto, 4200-450 Porto, Portugal; jneves@fade.up.pt

3 The Research Centre in Sports Sciences, Health Sciences and Human Development (CIDESD), 5001-801 Vila Real, Portugal; rafaeloliveira@esdrm.ipsantarem.pt

4 Research Unit for Sport and Physical Activity, Faculty of Sport Sciences and Physical Education, University of Coimbra, 3000-370 Coimbra, Portugal; hg.sarmento@gmail.com

5 Faculty of Human Kinetics, 1649-004 Lisboa, Portugal; mariosa04@hotmail.com

6 Sports Science School of Rio Maior-Polytechnic Institute of Santarém, 2140-413 Rio Maior, Portugal

7 Life Quality Research Centre, 2140-413 Rio Maior, Portugal

check for

updates

Citation: Ribeiro, J.; Afonso, J.; Camões, M.; Sarmento, H.; Sá, M.; Lima, R.; Oliveira, R.; Clemente, F.M. Methodological Characteristics, Physiological and Physical Effects, and Future Directions for Combined Training in Soccer: A Systematic Review. Healthcare 2021, 9, 1075. https: / / doi.org/10.3390/

healthcare 9081075

Academic Editor: Pedram Sendi

Received: 7 July 2021

Accepted: 17 August 2021

Published: 20 August 2021

Publisher's Note: MDPI stays neutral with regard to jurisdictional claims in published maps and institutional affiliations.

Copyright: (c) 2021 by the authors. Licensee MDPI, Basel, Switzerland. This article is an open access article distributed under the terms and conditions of the Creative Commons Attribution (CC BY) license (https:// creativecommons.org/licenses/by/ $4.0 /)$.
8 Instituto de Telecomunicações, Delegação da Covilhã, 1049-001 Lisboa, Portugal

* Correspondence: filipe.clemente5@gmail.com

\begin{abstract}
Combined training (CT) may combine strength and endurance training within a given time period, but it can also encompass additional protocols consisting of velocity, balance, or mobility as part of the same intervention. These combined approaches have become more common in soccer. This systematic review was conducted to (1) characterize the training protocols used in CT studies in soccer, (2) summarize the main physiological and physical effects of CT on soccer players, and (3) provide future directions for research. Methods: A systematic review of Cochrane Library, PubMed, Scopus, SPORTDiscus, and Web of Science databases was performed according to the Preferred Reporting Items for Systematic Reviews and Meta-Analyses (PRISMA) guidelines. The PICOS were defined as follows: P (soccer players of any age or sex); I (CT combining strength and endurance or sprinting or balance or mobility training); C (the control group (whenever applicable), with or without comparative interventions in addition to usual soccer training); $\mathrm{O}$ (acute and/or chronic responses: biochemical, physiological and physical); $\mathrm{S}$ (must have at least two groups, either randomized or non-randomized). The database search initially identified 79 titles. From those, eight articles were deemed eligible for the systematic review. Three studies analyzed acute responses to concurrent training, while the remaining five analyzed adaptations to CT. In those tested for acute responses, physiological (hormonal) and physical (strength and power external load, internal load) parameters were observed. Adaptations were mainly focused on physical parameters (strength and power, sprints, jumps, repeated sprint ability, aerobic, change-of-direction), with relatively little focus on physiological parameters (muscle architecture). Short-term responses to CT can affect hormonal responses of testosterone after resistance training with internal and external load. In turn, these responses' effects on strength and power have produced mixed results, as have adaptations. Specifically, strength and hypertrophy are affected to a lesser extent than speed/power movements. Nevertheless, it is preferable to perform CT before endurance exercises since it is a limiting factor for interference. Volume, intensity, rest between sessions, and athletes' fitness levels and nutrition dictate the degree of interference.
\end{abstract}

Keywords: soccer; athletic performance; strength training; high-intensity interval training; resistance training 


\section{Introduction}

Combined training (CT) combines different modalities of training, often involving both strength/resistance and endurance training to improve muscular strength, power, and aerobic capacity and power [1]. CT can be done within the same training session or during independent sessions [2]. However, other combinations consisting of strength and velocity, balance, or mobility can also be considered within a CT regimen. CT can be helpful in specific contexts, such as in intermittent sports that require more than one determinant physical quality to achieve favorable athletic performance [3].

Due to its high metabolic, physiological and physical demands [4,5], soccer is an example of a sport in which CT can be employed [6,7], considering that an optimal strength and endurance program is essential. The game of soccer consists of periods of low- to moderate-intensity, interspaced by high-intensity or all-out efforts [8]. The vast majority of a soccer match is spent performing low-intensity activities, which can represent almost $90 \%$ of all actions performed [9]. Despite the prevalence of low-intensity actions, high-intensity actions such as accelerations, sprints, jumps, duels, and kicks strongly influence a team's and player's performance, considering specific important moments (e.g., counter-attacks, transitions, goals) [10] that can change a game's outcome [11].

Considering that the high-intensity and determinant actions that occur in a match are strength and power-dependent, it is expectable that specific strength and power training protocols are part of the weekly training plan of the players [12]. Nevertheless, and considering the prevalence of low-to-vigorous running over $90 \mathrm{~min}$, endurance training can also be achieved using different continuous and intermittent methods [13]. Other determinant qualities such as maximal velocity, agility, and balance might also be important in sustaining the demands of the game $[14,15]$.

Since endurance training seems insufficient to guarantee that an appropriate stimulus for improving neuromuscular capacity is introduced, resistance training (RT) has been highly recommended to complement the field-based training sessions (which are usually focused on endurance stimuli and tactical/technical development) [16,17]. A well-developed strength capacity can help soccer players sustain other capacities, considering the relationships between strength and jumping or sprinting performance [16]. Additionally, strength training may help soccer players improve their running economy [18], which is important for mitigating the effects of fatigue, supporting the ability to repeat high-intensity efforts [19], and improving change-of-direction actions [3].

However, the impact of CT is not limited to the potential physiological or physical adaptations (or the chronic effects derived from a specific period in which a stimulus is provided). CT also produces a given acute or transitory effect in which the stimulus temporarily changes physiological or physical dimensions. While some reviews have addressed the effects of CT in performance outcomes and physiological changes $[20,21]$ in different sports [22-24], a characterization of training protocols in soccer is lacking. For instance, it was found in non-soccer athletes that power is the most important variable that can be affected by CT [20]. Additionally, it was found that high volume, moderate, continuous and frequent endurance training negatively affect the resistance training-induced adaptations, probably by inhibition of the Protein kinase B-mammalian target of rapamycin pathway activation of the adenosine monophosphate-activated protein kinase; on the other hand, it was found that short bouts of high-intensity interval training or sprint interval training could minimize the negative effects of concurrent training [21].

Since factors such as training intensity, frequency, and volume can strongly influence training adaptations, it is vital to understand how CT is implemented in soccer.

For the above-mentioned reasons, there is a need for a systematic review. Such a review could help to characterize experimental CT protocols in soccer players and provide a general overview of the physiological and physical effects on the players. A scoping review may help coaches to achieve an overview of the possibilities for applying CT in soccer. This kind of review could also help researchers define future projects and intervention directions. Therefore, the aim of the present scoping review was threefold: 
(1) to characterize the main elements of CT studies (e.g., training protocols) conducted in soccer, (2) to summarize the main physiological and physical effects of CT on soccer players, and (3) to provide directions for future research.

\section{Methods}

This systematic followed the Cochrane Collaboration guidelines [25]. The scoping review strategy was conducted according to PRISMA (Preferred Reporting Items for Systematic Reviews and Meta-analyses) guidelines [26]. The P.I.C.O.S. (Population or problem; Intervention or exposure; Comparison; Outcome; Study design) is: P (soccer players of any age or sex); I (CT combining strength and endurance or sprinting or balance or mobility training); C (if applicable, control group, with or without comparative interventions in addition to usual soccer training); $\mathrm{O}$ (acute and/or chronic responses: biochemical, physiological and physical); $S$ (must have at least two groups - randomized or non-randomized). The protocol was published in INPLASY (International Platform of Registered Systematic Review and Meta-analysis Protocols) with the identification number INPLASY2020110132 and DOI:10.37766/inplasy2020.11.0132.

\subsection{Eligibility Criteria}

The inclusion and exclusion criteria based on PICOS can be found in Table 1.

Table 1. Inclusion and exclusion criteria.

\begin{tabular}{|c|c|c|}
\hline PICOS & Inclusion Criteria & Exclusion Criteria \\
\hline Population & Soccer players of any age or sex without injury or illness reported & $\begin{array}{l}\text { Others sports than soccer, players with } \\
\text { injuries or illness }\end{array}$ \\
\hline Intervention & $\begin{array}{l}\text { Intervention is } \mathrm{CT} \text { using strength (e.g., including any type of structured } \\
\text { strength training, namely, resistance training, plyometrics, calisthenics) } \\
\text { and endurance or sprinting or balance or mobility training }\end{array}$ & $\begin{array}{l}\text { Interventions not including strength and } \\
\text { endurance or sprinting or balance or } \\
\text { mobility training in the same protocol }\end{array}$ \\
\hline Comparator & $\begin{array}{l}\text { Compared with control (passive control with just regular field-based } \\
\text { training and no other additional program reported) or other } \\
\text { intervention group (active control with field-based training and other } \\
\text { intervention protocol not consisting in } \mathrm{CT} \text {, or even single interventions } \\
\text { of strength or endurance training) }\end{array}$ & $\begin{array}{l}\text { No compared with passive control or } \\
\text { other intervention group }\end{array}$ \\
\hline Outcome & $\begin{array}{l}\text { At least one pre- or post-acute and/or chronic outcome (acute response: } \\
\text { immediate response of a physical or physiological variable in response } \\
\text { to the exercise; chronic response: adaptations promoted by the training } \\
\text { intervention, consisting in permanent changes in physical or } \\
\text { physiological variables) related to physiological (e.g., heart rate } \\
\text { responses, blood lactate concentrations, oxygen uptake, rate of } \\
\text { perceived exertion) and physical (e.g., strength and power, speed, } \\
\text { change-of-direction, aerobic capacity) measures }\end{array}$ & $\begin{array}{l}\text { No pre-post data related to acute and/or } \\
\text { chronic physiological and } \\
\text { physical measures }\end{array}$ \\
\hline $\begin{array}{l}\text { Study } \\
\text { design }\end{array}$ & $\begin{array}{l}\text { The study designs must have at least two groups (randomized or } \\
\text { non-randomized). }\end{array}$ & $\begin{array}{l}\text { Descriptive studies or } \\
\text { observational analytic. }\end{array}$ \\
\hline $\begin{array}{l}\text { Additional } \\
\text { criteria }\end{array}$ & Only original and full-text studies written in English & $\begin{array}{l}\text { Written in other language than English. } \\
\text { Other article types than original (e.g., } \\
\text { reviews, letters to editors, trial } \\
\text { registrations, proposals for protocols, } \\
\text { editorials, book chapters and } \\
\text { conference abstracts). }\end{array}$ \\
\hline
\end{tabular}

The screening of the title, abstract and reference list of each study to locate those which were potentially relevant was independently performed by the two authors (F.M.C. and J.A.). Additionally, they reviewed the full version of the included papers in detail to identify articles that met the selection criteria. An additional search within the reference lists of the included records was conducted to retrieve additional relevant studies. A discussion was 
made in the cases of discrepancies regarding the selection process with a third author (J.R.). Possible errata for the included articles were considered.

\subsection{Information Sources and Search}

Electronic databases (Cochrane Library, PubMed, Scopus, SPORTDiscus and Web of Science) were searched for relevant publications prior to 3 December 2020. Keywords and synonyms were entered in various combinations in title and/or abstract for the following terms: ("Soccer" OR "Football") AND ("concurrent training" OR "combined training" OR "cross training"). Additionally, the reference lists of the studies retrieved were manually searched to identify potentially eligible studies not captured by the electronic searches. Finally, an external expert was contacted in order to verify the final list of references included in this scoping review in order to understand if there was any study that was not detected through our research.

\subsection{Data Extraction}

Data extraction was prepared in Microsoft Excel sheet (Microsoft Corporation, Readmon, WA, USA) in accordance with the Cochrane Consumers and Communication Review Group's data extraction template [27]. The Excel sheet was used to assess inclusion requirements and subsequently tested for all selected studies. The process was independently conducted by the two authors (F.M.C. and J.A.). Any disagreement regarding study eligibility was resolved in discussion. Full text articles excluded, with reasons, were recorded. All the records were stored in the sheet.

\subsection{Data Items}

The main outcomes defined for data extraction were: (i) acute or immediate effects related to CT exposure (internal load, external load, hormonal responses and strength and power); and (ii) adaptations related to CT interventions (pre-post differences in strength and power, muscle architecture, aerobic performance, sprinting, jumping, change-of-direction (COD) and repeated sprint ability (RSA)). The acute or immediate effects are related to immediate and transitory effects of CT in internal load (e.g., psychophysiological responses [28], heart rate, rate of perceived exertion (RPE), blood lactate), external load (e.g., physical demands related to the exercise [28], distances covered at different speed thresholds, accelerations, decelerations), hormonal responses (e.g., testosterone, growth hormone) and strength and power (e.g., vertical jump height using tests as squat, countermovement or drop jumps). The adaptations represent a structural change in fitness status in which the following measures were extracted: (i) strength and power (e.g., repetition maximum); (ii) muscle architecture (e.g., changes in fascicle angle, muscle thickness); (iii) aerobic performance (e.g., maximal oxygen uptake, distance in field-based tests); (iv) sprinting (e.g., time in specific distances, as 10-, 20-, 30-m); (v) jumping (e.g., vertical jump in tests such as squat, countermovement or drop jump; horizontal jumps); (vi) COD (e.g., time in tests such as 5-0-5, pro-agility, T-test); and (vii) RSA (e.g., time or fatigue index in tests of repeated-sprints in different distances).

Additionally to the main outcomes, the following information was extracted: (i) type of study design, number of participants (n), age-group (youth, adults or both), sex (men, women or both), competitive level (if available), and type of original articles included (study design).

\subsection{Assessment of Methodological Quality}

The version 2 of the Cochrane risk-of-bias tool for randomized trials (RoB2) [29] was used to assess the risk of bias in those included. Five dimensions are inspected in this assessment tool: (i) bias arising from the randomization process; (ii) bias due to deviations from intended interventions; (iii) bias due to missing outcome data; (iv) bias in measurement of the outcome; and (v) bias in selection of the reported result. Using RoB2, a qualitative synthesis was performed. Two of the authors (J.A. and H.S.) independently 
assessed the risk of bias. Any disagreement in the rating was resolved through discussion and by a third author (F.M.C.).

The Cochrane risk of bias in non-randomized studies of interventions (ROBINS-I) was used to assess the risk of bias in included non-randomized intervention studies [30]. Three domains are analyzed in this assessment tool: (i) pre-intervention (bias due to confounding; bias in selection of participants into the study); (ii) at intervention (bias in classification of interventions); and (iii) post-intervention (bias due to deviations from intended interventions; bias due to missing data; bias in measurement of outcomes; bias in selection of the reported results). Two of the authors (JA and HS) independently assessed the risk of bias. Any disagreement in the rating was resolved through discussion and by a third author (F.M.C.).

\section{Results}

\subsection{Study Identification and Selection}

The searching of databases identified a total of 79 titles. These studies were then exported to reference manager software (EndNoteTM X9, Clarivate Analytics, Philadelphia, PA, USA). The screening process and the flow to arrive at the included articles can be observed in Figure 1.
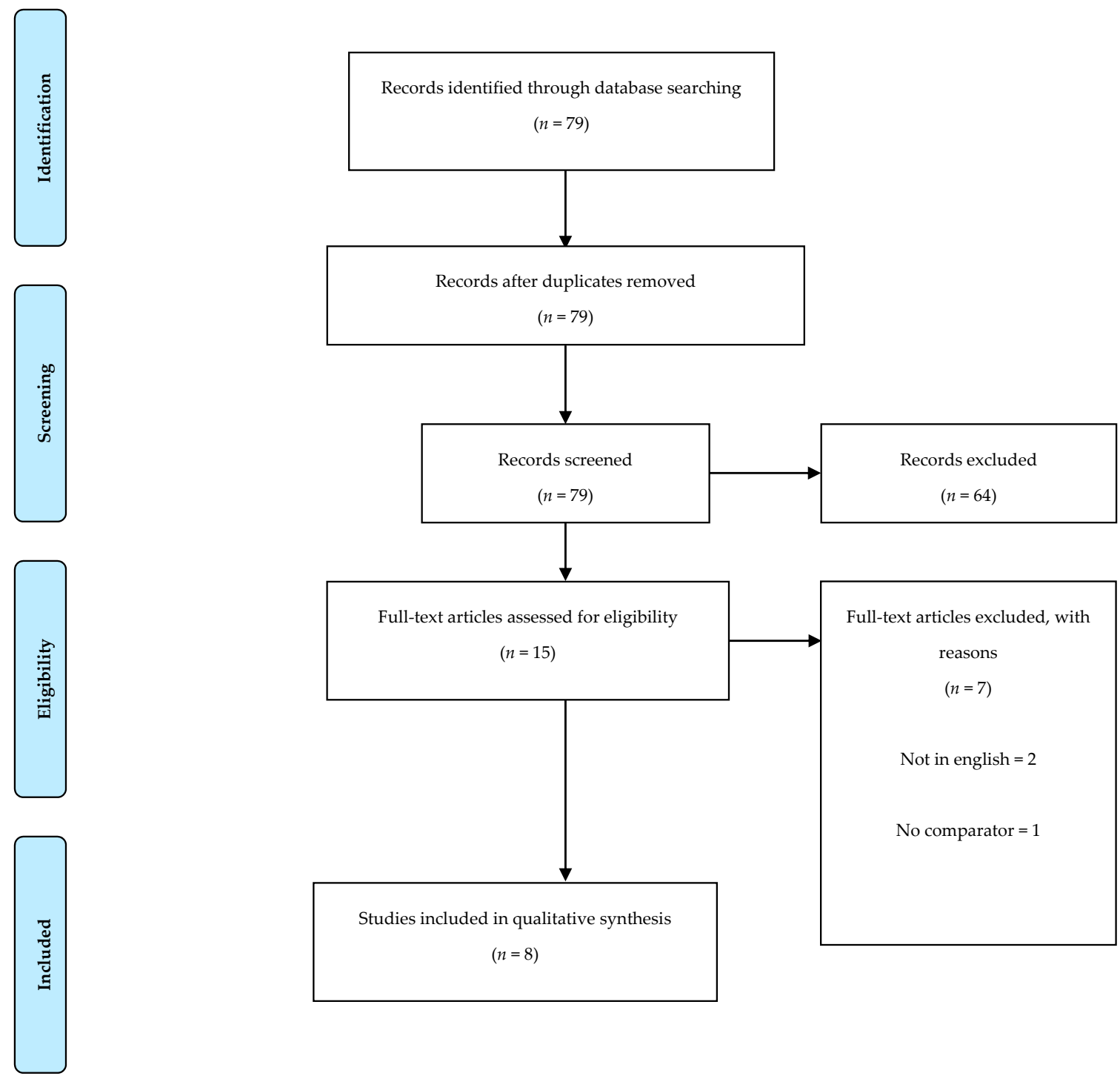

Figure 1. PRISMA flow diagram highlighting the selection process for the studies included in the current systematic review. 


\subsection{Study Characteristics and Training Protocols}

Eight studies were included in this review $[6,7,31-36]$, three of which $[6,31,32]$ looked at acute responses and five of which $[7,33-36]$ considered chronic adaptations. Three of the studies on chronic adaptations involved teenagers [7,33,34], and one involved young adults [36]. Of the studies of acute responses, two focused on young adults [6,31], one focused on teenagers [32], and one focused on children [35]. Athletes' fitness levels varied from healthy male volunteers (control group) in Kotzamanidis's study [7] to lowerlevel athletes [7,34] moderate-level (or semi-professional) athletes [31], and high-level (or professional) athletes $[6,32,33,35,36]$. The characteristics of the included studies can be found in Table 2.

CT training was applied in all the studies [6,7,31-36]. Strength and endurance (either soccer-specific endurance, HIT, or a combination of both) were combined in [6,33-36], with interventions lasting between five [33,36] and 12 weeks [35], with [34] lasting six weeks and [6] lasting10 weeks. Other studies had different training modalities, such as a combination of speed and plyometrics [34] or strength and speed [7] lasting six and 13 weeks, respectively. The two other studies [31,32] also combined strength and endurance, but subjects were submitted to just two training interventions with $72 \mathrm{~h}$ of rest between them. The details of the interventions and training protocols can be found in Table 3.

A conceptual overview elaborated by the authors of this scoping review can be seen in Figure 2. This overview aims to systematize the complexity of the field and to present it in an intelligible manner.

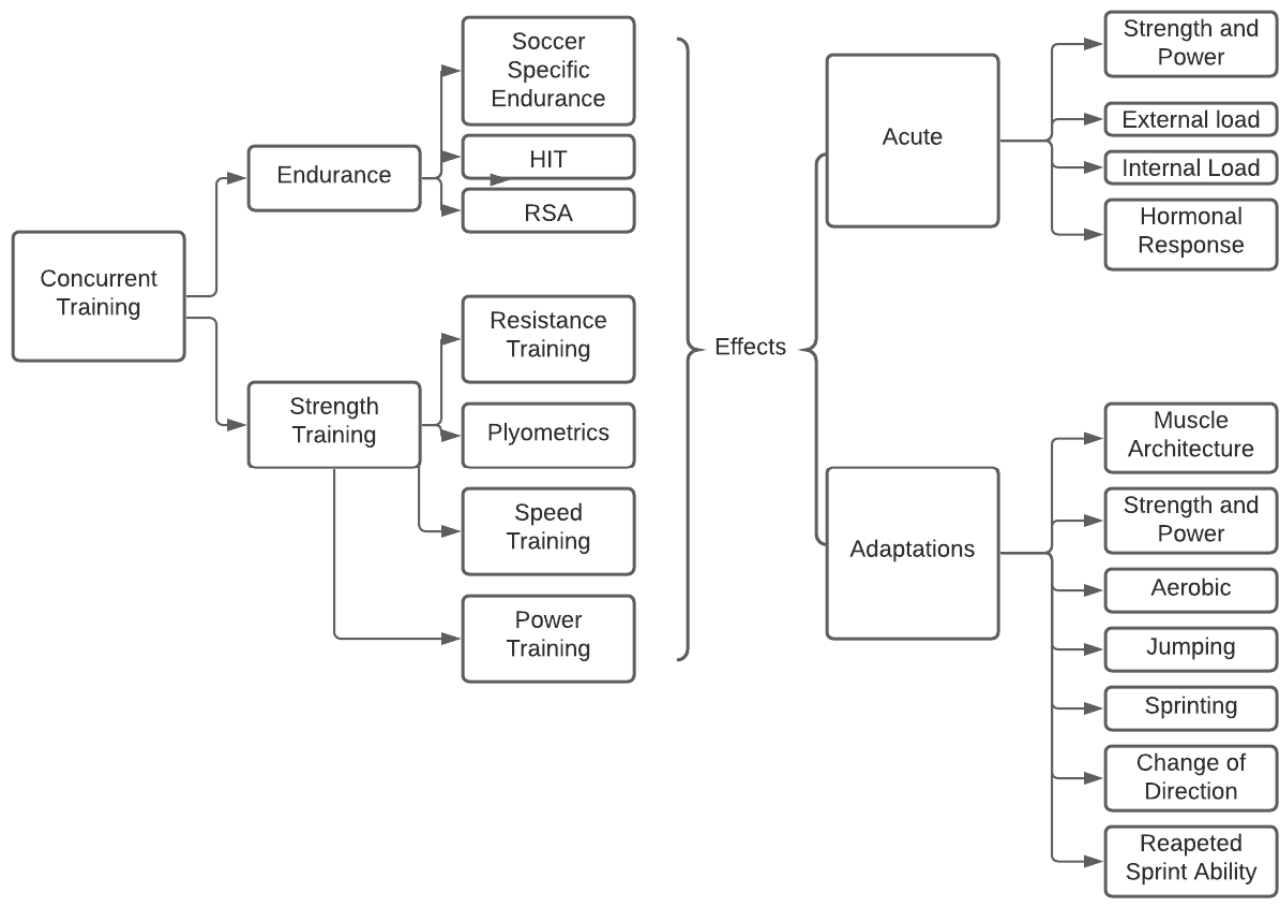

Figure 2. Concept map. 
Table 2. Characteristics of the included studies.

\begin{tabular}{|c|c|c|c|c|c|c|c|}
\hline Study & $N$ & Age (SD) & $\begin{array}{c}\text { Competitive } \\
\text { Level }\end{array}$ & Design & Outcomes & Tests Used in the Original Studies & Measures Extracted from the Tests \\
\hline [33] & 15 & $17.3 \pm 1.6$ & $\begin{array}{l}\text { English } \\
\text { Premier } \\
\text { League }\end{array}$ & $\begin{array}{l}\text { Players where split in two groups. CT training was } \\
\text { employed in both groups } 2 x / \text { week for } 5 \text { weeks, } \\
\text { alternating CT order. }\end{array}$ & $\begin{array}{l}\text { Chronic responses: muscle } \\
\text { morphology, jumping } \\
\text { ability, sprint ability, } \\
\text { strength. }\end{array}$ & $\begin{array}{ll}- & \text { Muscle architecture and muscle } \\
\text { thickness } \\
- & \text { SJ } \\
- & \text { CMJ } \\
- & \text { Sprinting speed } \\
- & \text { Back Squat Strength } \\
- & \text { Isokinetic strength } \\
- & \text { measurements } \\
- & \text { Quadriceps maximal isometric } \\
& \text { voluntary contraction } \\
- & \text { Isometric loading Rate }\end{array}$ & $\begin{array}{ll}- & \text { Muscle thickness }(\mathrm{cm}) \\
- & \text { Muscle fascicule angle of pennation }\left({ }^{\circ}\right) \\
- & \text { Muscle fascicule length }(\mathrm{cm}) \\
- & \text { Vertical Jump Height }(\mathrm{cm}) \\
- & \text { 10-m sprint time }(\mathrm{s}) \\
- & \text { 30-m sprint time }(\mathrm{s}) \\
- & \text { Back Squat Load Lifted }(\mathrm{kg}) \\
- & \text { Peak Isometric Force }(\mathrm{N}) \\
- & \text { Isometric Loading Rate } \\
- & \text { QuadCon60 } \\
- & \text { QuadCon180 } \\
- & \text { QuadEcc120 } \\
- & \text { HamCon60 } \\
- & \text { HamCon180 } \\
- & \text { HamEcc120 } \\
- & \text { Hecc/Qcon60 } \\
- & \text { Hecc/Qcon120 } \\
\end{array}$ \\
\hline [6] & 21 & $26 \pm 04$ & $\begin{array}{l}\text { English “Cham- } \\
\text { pionship" }\end{array}$ & $\begin{array}{l}\text { 10-week observational study. Internal data (sRPE } \\
\text { and heart rate) and external load (GPS, volume RT), } \\
\text { training modality frequency and dietary intake. }\end{array}$ & $\begin{array}{l}\text { Acute responses: } \\
\text { Internal load, external } \\
\text { load. }\end{array}$ & $\begin{array}{c}\text { Observational study. } \\
\text { Heart Rata data } \\
\text { GPS Data } \\
\text { Training Load } \\
\text { RT Volume Load } \\
\text { RT Training Intensity (1RM Based) }\end{array}$ & $\begin{array}{ll}- & \text { Football-specific Start Time } \\
- & \text { Football Duration (m) } \\
- & \text { HRmax } 85 \%-100 \%(\mathrm{~min}) \\
- & \text { Average sRPE-TL (AU) } \\
- & \text { sRPE (AU) } \\
- & \text { Total Distance travelled (m) } \\
- & \text { RT start time } \\
- & \text { RT Duration (m) } \\
- & \text { RT Volume load }(\mathrm{kg}) \\
- & \text { Frequency of upper body training }(n) \\
- & \text { Frequency of lower body training }(n) \\
- & \text { Frequency of lower and upper body training }(n) \\
- & \text { Frequency of sessions at 4 RM, } 5 \text { RM,6 RM, } 8 \\
- & \text { RM, 10 RM and 12 RM }(n) \\
- & \text { Recovery range between bouts (min) } \\
- & \text { Recovery period between bouts (min) } \\
\end{array}$ \\
\hline [32] & 13 & $17.0 \pm 0.2$ & $\begin{array}{l}\text { English } \\
\text { Premier } \\
\text { League }\end{array}$ & $\begin{array}{l}\text { Athletes were taken twice a week to the laboratory in } \\
2 \text { consecutive weeks. } \\
\text { Week } 1 \text {, baseline testing, week 2, two different CT } \\
\text { trails were employed (CT1 and CT2). Before, during } \\
\text { and after each trail, venous blood samples were } \\
\text { collected }\end{array}$ & $\begin{array}{l}\text { Acute responses: } \\
\text { Hormonal response }\end{array}$ & Venous Blood Samples & $\begin{array}{ll}- & \text { Serum growth hormone }(\mathrm{ug} / \mathrm{L}) \\
- & \text { Total Testosterone }(\mathrm{mmol} / \mathrm{L}) \\
- & \text { Cortisol }(\mathrm{mmol} / \mathrm{L})\end{array}$ \\
\hline [34] & 24 & $\begin{array}{l}\mathrm{CG}=17.6 \pm 0.4 \\
\mathrm{CDG}=17.8 \pm 0.8 \\
\mathrm{CWG}=17.8 \pm 0.6\end{array}$ & $\begin{array}{l}\text { Second } \\
\text { division, Iran } \\
\text { League }\end{array}$ & $\begin{array}{l}\text { All groups attended to technical/tactical soccer } \\
\text { training during } 6 \text { weeks CWD performed on } \\
\text { Tuesday plyometric training and on Saturdays Speed } \\
\text { training. The CDG training included all three } \\
\text { modalities in the same session (Saturdays). }\end{array}$ & $\begin{array}{l}\text { Chronic responses: agility } \\
\text { ability, sprint ability, power } \\
\text { endurance }\end{array}$ & $\begin{array}{l}505 \text { COD Test } \\
\text { Repeated Sprint Ability Test }\end{array}$ & $\begin{array}{ll}- & \text { Agility time }(\mathrm{s}) \\
- & 30 \mathrm{~m} \text { sprint time }(\mathrm{s}) \\
- & \text { Sprint decay }\end{array}$ \\
\hline
\end{tabular}


Table 2. Cont

\begin{tabular}{|c|c|c|c|c|c|c|c|}
\hline Study & $N$ & Age (SD) & $\begin{array}{c}\text { Competitive } \\
\text { Level }\end{array}$ & Design & Outcomes & Tests Used in the Original Studies & Measures Extracted from the Tests \\
\hline [7] & 35 & $\begin{array}{c}\mathrm{COM}=17.0 \pm 1.1 \\
\mathrm{STR}=17.1 \pm 1.1 \\
\mathrm{CG}=17.8 \pm 0.3\end{array}$ & $\begin{array}{l}\text { Healthy male } \\
\text { volunteers } \\
\text { (CG) and } \\
\text { soccer players } \\
\text { (COM and } \\
\text { STR) }\end{array}$ & $\begin{array}{l}\text { During } 13 \text { weeks, } 2 \text { groups of followed one STR, and } \\
\text { COM. }\end{array}$ & $\begin{array}{l}\text { Chronic responses: } \\
\text { Strength, sprint ability, } \\
\text { jumping ability. }\end{array}$ & $\begin{array}{ll}- & \text { 1RM Squat } \\
- & \text { 1RM Step up } \\
- & \text { 1RM Leg Curl } \\
- & 30 \mathrm{~m} \text { Sprint } \\
- & \text { Squat Jump } \\
- & \text { Countermovement Jump } \\
- & \text { Drop Jump } 40 \mathrm{~cm} \\
\end{array}$ & $\begin{array}{ll}- & \text { Squat load lifted }(\mathrm{kg}) \\
- & \text { Step up load lifted }(\mathrm{kg}) \\
- & \text { Leg Curl load lifted }(\mathrm{kg}) \\
- & \text { 30-m sprint time }(\mathrm{s}) \\
- & \text { Jump height }(\mathrm{cm})\end{array}$ \\
\hline [35] & 57 & $13.7 \pm 0.5$ & $\begin{array}{l}\text { First Division } \\
\text { Tunisian }\end{array}$ & $\begin{array}{l}\text { For } 12 \text { weeks } 3 \text { groups trained in different training } \\
\text { sequence. } \\
\text { SE in a single session, ES in a single session, both } \\
2 / \text { week and ASE ( } 4 x / \text { week). }\end{array}$ & $\begin{array}{l}\text { Chronic responses: } \\
\text { Aerobic capacity, strength, } \\
\text { jumping ability, power, } \\
\text { agility ability. }\end{array}$ & $\begin{array}{ll}- & \text { Yo-Yo IR1 } \\
- & \text { Progressive maximal field test } \\
& \text { (Vam-eval, VAM) } \\
- & \text { Bench Press 1RM Test } \\
- & \text { Squat 1RM Test } \\
- & \text { CMJ } \\
- & \text { SJ } \\
- & \text { 5Jump Test for Distance (5JT) } \\
- & \text { Medicine ball throw } \\
- & 10 \text { and 30-m sprint } \\
- & \text { Agility-15 m } \\
- & \text { Agility-15 m with ball } \\
\end{array}$ & $\begin{array}{ll}- & \text { Maximal high-intensity intermittent endurance } \\
& \text { running capacity }(\mathrm{m}) \\
- & \text { Maximal aerobic speed }(\mathrm{km} / \text { hour }) \\
- & \text { Bench Load lifted }(\mathrm{kg}) \\
- & \text { Squat Load Lifted }(\mathrm{kg}) \\
- & \text { Jump with countermovement height }(\mathrm{cm}) \\
- & \text { Jump height without countermovement }(\mathrm{cm}) \\
- & 5 \text { jumps distance }(\mathrm{cm}) \\
- & \text { Ball Throw Distance }(\mathrm{cm}) \\
- & \text { Agility } 15 \mathrm{~m} \text { time with and without ball }(\mathrm{s})\end{array}$ \\
\hline [36] & 18 & $23 \pm 4$ & $\begin{array}{l}\text { Professional } \\
\text { and semi- } \\
\text { professional } \\
\text { Swedish I } \\
\text { Division }\end{array}$ & $\begin{array}{l}\text { A 5-week with two groups, one would perform HIT } \\
\text { followed by STR the other STR followed by HIT. } \\
\text { CT sessions were carried out } 3 \text { times per week } \\
\text { (Tuesdays, Thursday and Fridays), } 30 \text { min of HIT or } \\
\text { STR followed by the remaining modality. Soccer } \\
\text { technical and tactical field sessions were performed } \\
\text { on Mondays and Wednesdays. }\end{array}$ & $\begin{array}{l}\text { Chronic responses: Body } \\
\text { composition, jumping } \\
\text { ability, strength, agility } \\
\text { ability, sprint, aerobic } \\
\text { capacity, power endurance }\end{array}$ & $\begin{array}{ll}- & \text { Body composition) } \\
- & \text { Countermovement Jump } \\
& \text { (Abalakov) } \\
- & \text { 3 RM Squats (parallel) } \\
- & \text { 3 RM Lunges/split squat } \\
- & \text { RM chin-ups } \\
- & \text { RM Hanging sit up } \\
- & 40 \mathrm{~m} \text { modified T-Test } \\
- & \text { Yo-Yo IR2) } \\
- & 10 \mathrm{~m} \text { sprint } \\
- & 6 \times 30 \mathrm{~m} \text { repeated sprint test } \\
- & \text { Soccer specific flexibility test }\end{array}$ & $\begin{array}{ll}- & \text { Body Fat }(\%) \\
- & \text { Fat }(\mathrm{kg}) \\
- & \text { Lean mass (\%) } \\
- & \text { Lean mass }(\mathrm{kg}) \\
- & \text { Jump height }(\mathrm{cm}) \\
- & \text { Maximum load lifted for 1RM Squat }(\mathrm{kg}) \\
- & \text { Maximum load lifted for 1RM Lunges }(\mathrm{kg}) \\
- & \text { Number of repetitions performed Chin ups }(n) \\
- & \text { Number repetitions performed } \\
- & \text { Change of direction ability /agility }(\mathrm{s}) \\
- & \text { 10-m sprint time (s) } \\
- & \text { Distance covered (m) } \\
- & \text { Sum of } 6 \text { sprints }(\mathrm{s}) \\
- & \text { Performance decrement }(\%) \\
- & \text { Iliopsoas } \\
- & \text { Hamstrings }\end{array}$ \\
\hline
\end{tabular}


Table 2. Cont

\begin{tabular}{|c|c|c|c|c|c|c|c|}
\hline Study & $N$ & Age (SD) & $\begin{array}{c}\text { Competitive } \\
\text { Level }\end{array}$ & Design & Outcomes & Tests Used in the Original Studies & Measures Extracted from the Tests \\
\hline [31] & 14 & $22.1 \pm 3.1$ & $\begin{array}{c}\text { Semi- } \\
\text { Professional }\end{array}$ & $\begin{array}{l}2 \mathrm{CT} \text { training order, either SSG training followed by } \\
\text { STR (SSG + RES) or STR followed by SSG, both with } \\
\text { a 2-h interval. Players were given } 72 \mathrm{~h} \text { of rest } \\
\text { between CT sessions. Data was collected before }(0 \mathrm{~h}) \\
\text { and after }(24 \mathrm{~h} \text { ) in both protocols. Saliva was also } \\
\text { collected prior to the second training session }(+2 \mathrm{~h}) \\
\text { during both protocols so assess readiness to } \\
\text { undertake the second session of the day) }\end{array}$ & $\begin{array}{l}\text { Acute responses: } \\
\text { Hormonal response, } \\
\text { power, internal load, } \\
\text { external load. }\end{array}$ & $\begin{array}{ll}- & \text { CMJ (Abalakov) } \\
- & \text { Bam + Questionnaire } \\
- & \text { Saliva samples } \\
- & \text { RPE } \\
- & \text { GPS Data }\end{array}$ & $\begin{array}{ll}- & \text { Jump height }(\mathrm{cm}) \\
- & \text { Peak Power Output (w/kg) } \\
- & \text { Monitor Fatigue (AU) } \\
- & \text { Mood (AU) } \\
- & \text { Testosterone (ng/dl) } \\
- & \text { Cortisol (ng/dl) } \\
- & \text { Testosterone to Cortisol (AU) } \\
- & \text { Exercise intensity (AU) } \\
- & \text { Total distance (m) } \\
- & \text { High Speed Running (m) } \\
- & \text { Player Load (AU) }\end{array}$ \\
\hline
\end{tabular}

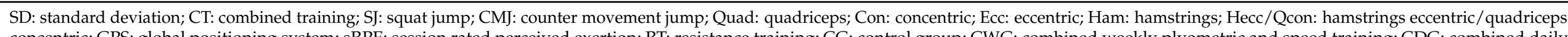

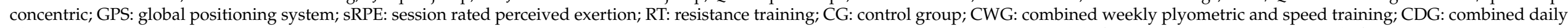

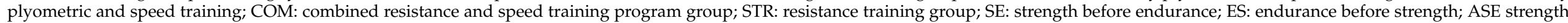

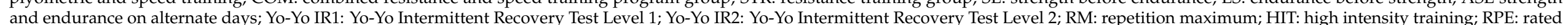
perceived exertion; SSG: small sided games.

Table 3. Characteristics of CT programmes in the included studies.

\begin{tabular}{|c|c|c|c|c|c|c|c|c|c|}
\hline Study & Duration (w) & $\mathrm{d} / \mathrm{w}$ & $\begin{array}{c}\text { CT } \\
\text { Sessions } \\
\text { Number } \\
\end{array}$ & $\begin{array}{l}\text { Total Number of } \\
\text { Sessions }\end{array}$ & $\begin{array}{l}\text { Strength } \\
\text { Training }\end{array}$ & $\begin{array}{l}\text { Other } \\
\text { Training }\end{array}$ & $\begin{array}{l}\text { Type of CT (Within or } \\
\text { Between Sessions) }\end{array}$ & Protocol of Strength Training & Protocol of the Other Training Method \\
\hline [33] & 5 weeks & $\begin{array}{c}2 \\
\text { days/week }\end{array}$ & 10 & $\begin{array}{l}20 \text { regular soccer } \\
\text { sessions }+5 \text { games }\end{array}$ & $\begin{array}{l}\text { Maximum } \\
\text { Strength }\end{array}$ & $\begin{array}{l}\text { Soccer } \\
\text { Specific } \\
\text { Endurance } \\
\text { Training }\end{array}$ & $\begin{array}{l}\text { Both groups did CT training } \\
\text { in the same day. Endurance }+ \\
\text { Strength group had } \sim 120^{\prime} \\
\text { difference between session, } \\
\text { while Strength + Endurance } \\
\text { group had } \sim 30^{\prime}-45^{\prime} \text { difference. }\end{array}$ & $\begin{array}{l}\text { Strength program consisted in } 4 \text { sets of } \\
6 \text { reps ( 85\% } 1 \text { RM) of Parallel Back } \\
\text { Squat, deadlift, stiff-leg deadlift and } \\
\text { front lunge. Also } 3 \text { sets of } 8 \text { reps of the } \\
\text { Nordic hamstring was performed. }\end{array}$ & $\begin{array}{c}\sim 20^{\prime} \text { dynamic warm up } \\
\sim 25^{\prime} \text { SSG }(4 \text { versus } 4 \text {, possession. Each game } \\
\text { lasted } 4^{\prime} \text { at an intensity } \sim 85-95 \% \text { Heart Rate } \\
\text { max. Between each game } 3^{\prime} \text { of active recovery } \\
\text { was allocated. Pitch size was } 37 \times 27 \text {.) } \\
10^{\prime} \text { of rest interval between SSG and Technical } \\
\text { and tactical work was given. } \\
\sim 50^{\prime} \text { Technical and tactical work }\end{array}$ \\
\hline [6] & 10 weeks & $\begin{array}{c}\text { Week } 1-3, \\
5-3 \text { days a } \\
\text { week. } \\
\text { Weeks } 4-10 \\
1 \text { day a week }\end{array}$ & 17 & $\begin{array}{l}49 \text { regular session }+ \\
11 \text { games }+17 \\
\text { Strength sessions }\end{array}$ & $\begin{array}{l}\text { Maximum } \\
\text { Strength }\end{array}$ & $\begin{array}{l}\text { Specific } \\
\text { Soccer } \\
\text { Endurance }\end{array}$ & $\begin{array}{l}\text { Resistance training followed } \\
\text { by Specific soccer endurance } \\
\text { or Specific soccer endurance } \\
\text { followed by resistance } \\
\text { training. } \\
\text { The order was not consistent } \\
\text { but always performed on the } \\
\text { same day. }\end{array}$ & $\begin{array}{c}\text { Upper body only }(n=8) \\
6 \mathrm{RM}, n=1 ; 8 \mathrm{RM}, n=3 ; 10 \mathrm{RM}, n=3 ; \\
12 \mathrm{RM}, \\
n=1 . \\
\text { Lower body only }(n=4) \\
6 \text { RM, } n=3 ; 8 \mathrm{RM}, n=1 . \\
\text { Full body }(n=5) \\
4 \mathrm{RM}, n=1 ; 5 \mathrm{RM}, n=3 ; 8 \mathrm{RM}, n=1 .\end{array}$ & $\begin{array}{l}\text { Soccer specific endurance was performed at } \\
10: 30 \text {, typically lasted } 74 \pm 5\end{array}$ \\
\hline
\end{tabular}


Table 3. Cont.

\begin{tabular}{|c|c|c|c|c|c|c|c|c|c|}
\hline Study & Duration (w) & $d / w$ & $\begin{array}{c}\text { CT } \\
\text { Sessions } \\
\text { Number }\end{array}$ & $\begin{array}{l}\text { Total Number of } \\
\text { Sessions }\end{array}$ & $\begin{array}{l}\text { Strength } \\
\text { Training }\end{array}$ & $\begin{array}{c}\text { Other } \\
\text { Training }\end{array}$ & $\begin{array}{l}\text { Type of CT (Within or } \\
\text { Between Sessions) }\end{array}$ & Protocol of Strength Training & Protocol of the Other Training Method \\
\hline [32] & 2 weeks & $\begin{array}{l}2 \text { days a } \\
\text { week }\end{array}$ & 4 & $\begin{array}{l}\text { There was no regular } \\
\text { soccer training, at } \\
\text { least described in the } \\
\text { article. } \\
4 \text { sessions }\end{array}$ & $\begin{array}{l}\text { Maximum } \\
\text { Strength }\end{array}$ & $\begin{array}{l}\text { Soccer } \\
\text { Specific } \\
\text { Endurance }\end{array}$ & $\begin{array}{l}\text { Soccer Specific Endurance } \\
\text { Training followed by } \\
\text { Resistance Training with } \\
\sim 105^{\prime} \text { difference between them } \\
\text { or Resistance training } \\
\text { followed by Soccer Specific } \\
\text { Endurance Training } \\
\text { performed in the same day } \\
\text { with } \sim 60^{\prime} \text { difference between } \\
\text { them. }\end{array}$ & $\begin{array}{l}\text { The strength training consisted of } 4 \text { sets } \\
\text { of } 6 \text { reps ( } 85 \% 1 \mathrm{RM}) \text { of Parallel Back } \\
\text { Squat, deadlift, stiff-leg deadlift and } \\
\text { front lunge. Also } 3 \text { sets of } 8 \text { reps of the } \\
\text { Nordic hamstring were performed. }\end{array}$ & $\begin{array}{l}\text { Soccer Specific Endurance Training consisted } \\
\text { in a dynamic warm up }\left(\sim 20^{\prime}\right) \text {, } \\
\text { small-sided-games }\left(\sim 25^{\prime}\right) \text { and a technical and } \\
\text { tactical work }\left(\sim 50^{\prime}\right) \text {. SSG involved a } 4 \mathrm{v} 4 \\
\text { possession format with a duration of } 4^{\prime} \text { at an } \\
\text { intensity of } \sim 85-95 \% \text { Heart Rate max. Pitch } \\
\text { size was } 37 \mathrm{~m} \times 27 \mathrm{~m} \text { and between each game, } \\
3^{\prime} \text { of active recovery were allocated. }\end{array}$ \\
\hline [34] & 6 weeks & $\begin{array}{l}\text { CWG } 2 \text { days } \\
\text { a week } \\
\text { CDG } 1 \text { day } \\
\text { per week }\end{array}$ & $\begin{array}{c}\text { CG }(n=0) \\
\text { CWG }(n=12) \\
\text { CDG }(n=6)\end{array}$ & $\begin{array}{l}\text { CG }(n=30) \\
\text { CWG }(n=42) \\
\text { CDG }(n=36)\end{array}$ & - & $\begin{array}{l}\text { Plyometric, } \\
\text { Speed, } \\
\text { Soccer } \\
\text { Specific } \\
\text { Endurance }\end{array}$ & $\begin{array}{l}\text { CWG group had two types of } \\
\text { CT training, on Tuesday, } \\
\text { plyometrics and soccer } \\
\text { specific endurance and on } \\
\text { Saturday speed and soccer } \\
\text { specific endurance withing } \\
\text { the same session. } \\
\text { The CDG group had CT } \\
\text { training also on Tuesday and } \\
\text { Saturday, but both speed and } \\
\text { plyometric were performed } \\
\text { concurrently with soccer } \\
\text { specific endurance within the } \\
\text { same session. }\end{array}$ & & $\begin{array}{l}\text { Both the CDG and CWG performed the same } \\
\text { Plyometric and Speed programs, the } \\
\text { difference was if it was on the same day (CDG) } \\
\text { or in the same week (CWD). } \\
\text { Plyometric training consisted in } 4 \text { exercises, in } \\
\text { two different vectors (vertical and horizontal) } \\
\text { with a bilateral and a unilateral version of the } \\
\text { plyometric. For all plyometric exercises } \\
\text { repetition scheme was between } 2 \text { and } 3 \text { reps, } \\
\text { with a weekly progression of one set per week } \\
\text { starting at } 2 \text { or } 3 \text { sets and ending with } 5 \text { or } \\
6 \text { sets. } \\
\text { Speed training consisted in } 10,20 \text { and } 30 \mathrm{~m} \\
\text { linear sprints starting with } 4,3 \text { and } 2 \text { sets } \\
\text { respectively, and a weekly progression of } 2 \\
\text { sets for the } 10 \text { and } 20 \mathrm{~m} \text { sprint and } 1 \text { set for the } \\
30 \mathrm{~m} \text {. Rest time between sets was } 30^{\prime \prime} \text { for the } \\
10 \mathrm{~m} \text { sprint, } 45^{\prime \prime} \text { for the } 20 \mathrm{~m} \text { and } 60^{\prime \prime} \text { for } 30 \mathrm{~m} \text {. } \\
\text { Also } 5 \text { and } 10 \mathrm{~m} \text { sprints with a } 180^{\circ} \text { COD were } \\
\text { employed. } 5 / 5 \text { and } 10 / 5 / 10 \text { with } 2 \text { sets with } \\
60^{\prime \prime} \text { rest and } 1 \text { set with } 120^{\prime \prime} \text { rest between sets, } \\
\text { respectively with a progression on adding a } \\
\text { set per week. }\end{array}$ \\
\hline [7] & 13 weeks & $\begin{array}{l}\text { Weeks } 1-4,3 \\
\text { times per } \\
\text { week. } \\
\text { Weeks 5-13, } \\
2 \text { times per } \\
\text { week. }\end{array}$ & 18 & $\begin{array}{l}\text { There was no regular } \\
\text { soccer training, at } \\
\text { least described in the } \\
\text { article. Only that } \\
\text { they were physically } \\
\text { active students or } \\
\text { soccer players. }\end{array}$ & $\begin{array}{l}\text { Maximum } \\
\text { Strength }\end{array}$ & $\begin{array}{c}\text { Speed } \\
\text { Training }\end{array}$ & $\begin{array}{l}\text { Strength training followed by } \\
\text { Speed Training withing the } \\
\text { same session. }\end{array}$ & $\begin{array}{l}\text { The intensities for each subperiod were } \\
8 \mathrm{RM}, 6 \mathrm{RM} \text { and } 3 \mathrm{RM} \text {, respectively. For } \\
\text { each selected intensity, } 4 \text { sets with } 3^{\prime} \text { of } \\
\text { rest between them were given. Loads } \\
\text { were increased whenever the subject } \\
\text { was able to perform more than the } \\
\text { target repetitions. }\end{array}$ & $\begin{array}{l}\text { Speed work was performed by doing } 4,5 \text { and } 6 \\
\text { for their respective subperiod. Maximal } \\
\text { repetitions of } 30 \mathrm{~m} \text { sprint were performed } \\
\text { with a } 3^{\prime} \text { rest between every repetition. }\end{array}$ \\
\hline
\end{tabular}


Table 3. Cont.

\begin{tabular}{|c|c|c|c|c|c|c|c|c|c|}
\hline Study & Duration (w) & $d / w$ & $\begin{array}{l}\text { CT } \\
\text { Sessions } \\
\text { Number }\end{array}$ & $\begin{array}{l}\text { Total Number of } \\
\text { Sessions }\end{array}$ & $\begin{array}{l}\text { Strength } \\
\text { Training }\end{array}$ & $\begin{array}{l}\text { Other } \\
\text { Training }\end{array}$ & $\begin{array}{l}\text { Type of CT (Within or } \\
\text { Between Sessions) }\end{array}$ & Protocol of Strength Training & Protocol of the Other Training Method \\
\hline [35] & 12 weeks & $\begin{array}{l}2 \text { days a } \\
\text { week for SE } \\
\text { and ES } \\
\text { groups. } \\
4 \text { days a } \\
\text { week for } \\
\text { ASE group }\end{array}$ & $\begin{array}{l}\text { SE and ES } \\
(n=24) \\
\text { ASE }(n=48)\end{array}$ & $\begin{array}{l}\text { SE and ES + regular } \\
\text { training }(n=72) \\
\text { ASE }+ \text { Regular } \\
\text { Training }(n=96)\end{array}$ & $\begin{array}{l}\text { Maximum } \\
\text { Strength, } \\
\text { Hypertro- } \\
\text { phy, } \\
\text { Power }\end{array}$ & $\begin{array}{l}\text { Plyometric, } \\
\text { Endurance }\end{array}$ & $\begin{array}{l}\text { Both groups, ES and SE } \\
\text { performed concurrent } \\
\text { training within the same } \\
\text { session (Tuesday and } \\
\text { Thursday), only a 15' recovery } \\
\text { period separate them. } \\
\text { ASE group performed } \\
\text { endurance on separate days. }\end{array}$ & $\begin{array}{l}\text { Strength training changed every } 4 \\
\text { weeks, ending up with } 3 \text { different } \\
\text { blocks, being the first two more focused } \\
\text { on strength and hypertrophy and the } \\
\text { third one more on power development. } \\
\text { The first two blocks consisted in a } \\
\text { mixture of compound and isolated } \\
\text { movements with } 3 \text { sets of } 10 \text { to } 15 \text { reps } \\
\text { and } 3 \text { sets of } 6 \text { to } 10 \text { reps respectively. } \\
\text { The last block used a more power } \\
\text { development approach including } \\
\text { Olympic lifting and plyometrics for } 3 \\
\text { sets of } 5 \text { to } 8 \text { reps. }\end{array}$ & $\begin{array}{l}\text { Endurance training intensity was prescribed } \\
\text { based on individual MAS. Training consisted } \\
\text { in } 2 \text { rounds of } 10-16 \text { sets of } 15^{\prime \prime} \text { of } \\
\text { high-intensity running with } 15^{\prime \prime} \text { passive } \\
\text { recovery at an intensity between } 110-120 \%\end{array}$ \\
\hline [36] & 5 weeks & $\begin{array}{l}3 \text { days per } \\
\text { week }\end{array}$ & 15 & $\begin{array}{l}25 \text { sessions, plus } 5 \\
\text { Pilates sessions }\end{array}$ & $\begin{array}{l}\text { Maximum } \\
\text { Strength } \\
\text { and Power }\end{array}$ & $\begin{array}{l}\text { Endurance, } \\
\text { Soccer } \\
\text { Specific } \\
\text { Endurance }\end{array}$ & $\begin{array}{l}\text { Endurance followed by } \\
\text { Strength or Strength followed } \\
\text { by Endurance } \\
\text { within the same session }\end{array}$ & $\begin{array}{l}\text { Strength session on Tuesday and } \\
\text { Thursday were gym based } \\
\text { compromised 2-3 sets of 5-10 reps with } \\
\text { a progression overload on resistance } \\
\text { exercises from } 75-90 \% 1 \text { RM over the } \\
\text { 5-week period. On Friday's sessions } \\
\text { were focused on power, explosivity and } \\
\text { core development, 3 sets of 3-20 } \\
\text { repetitions were completed depending } \\
\text { on the exercise, also, exercises were } \\
\text { performed in a super-set order. }\end{array}$ & $\begin{array}{l}\text { HIT on Tuesdays included a mix of intervals } \\
\text { lasting } 5-20^{\prime} \text { and rest periods lasting between } \\
10-90^{\prime} \text {. On Thursday, HIT involved repeated } \\
\text { explosive actions using ladders, hurdles and } \\
\text { multi-directional running. Lastly, on Friday, } \\
\text { involved a completion of } 4-5 \text { rounds of } 4-5^{\prime} \\
\text { work and } 2-3^{\prime} \text { rest, with players performing a } \\
\text { soccer-specific dribbling track for the first } 2 \\
\text { weeks and a } 3 \text { vs } 3 \text { small-sided game on a } 20 \times \\
30 \mathrm{~m} \text { pitch at a HRmax } 90-95 \% \text {. }\end{array}$ \\
\hline [31] & 2 weeks & $\begin{array}{l}1 \text { day per } \\
\text { week }\end{array}$ & 1 & 2 & $\begin{array}{l}\text { Maximum } \\
\text { Strength }\end{array}$ & $\begin{array}{l}\text { Soccer } \\
\text { Specific } \\
\text { Endurance }\end{array}$ & $\begin{array}{l}\text { Soccer Specific Endurance } \\
\text { followed by Strength Training } \\
\text { or Strength Training followed } \\
\text { by Soccer Specific Training } \\
\text { within the same day (2-h } \\
\text { difference) }\end{array}$ & $\begin{array}{c}\text { Strength Training included Back Squat, } \\
\text { Romanian } \\
\text { Deadlift and Barbell Hip Thrust. All } \\
\text { performed at an intensity of } 85 \% \text { of } \\
\text { 1RM for } 4 \text { sets of } 4 \text { with a } 4^{\prime} \text { of inter-set } \\
\text { recovery. Each exercise was preceded } \\
\text { by } 2 \text { sets of } 4 \text { repetitions at } 50 \% \text { and } \\
70 \% 1 \text { RM. }\end{array}$ & $\begin{array}{l}\text { Players performed } 6 \times 7^{\prime} \text { with } 2^{\prime} \text { rest between } \\
\text { each set to allow them to drink water. Pitch } \\
\text { size was } 24 \times 29 \text { with full-size goals. }\end{array}$ \\
\hline
\end{tabular}

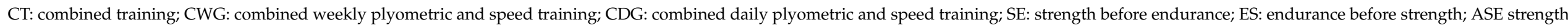
and endurance on alternate days; RM: repetition maximum; HIT: high intensity training; RPE: rated perceived exertion; SSG: small sided games; MAS: maximal aerobic speed. 


\subsection{Methodological Quality}

The randomized studies were assessed using RoB 2 instrument (Table 4). The assessment can be observed in Table 4. The two included studies presented an overall score of some concern. The dimensions of randomization process, measurement of the outcome and selection of the reported result were classified with some concerns.

Table 4. Assessment of the risk in randomized studies included with RoB 2.

\begin{tabular}{lcccccc}
\hline Study & D1 & D2 & D3 & D4 & D5 & Overall \\
\hline$[7]$ & $!$ & + & + & $!$ & $!$ & $!$ \\
{$[35]$} & $!$ & + & + & $!$ & $!$ & $!$
\end{tabular}

D1: randomization process; D2: deviations from intended interventions (ITT); D3: missing outcome data; D4 measurement of the outcome; D5: selection of the reported result; Green (+): low risk; Yellow (!): some concerns.

The non-randomized studies were assessed using the ROBINS-I (Table 5). The studies of [33] and [6] were classified as critical risk in the dimension of risk of bias judgements due to missing data, while the study of [6] was also classified as critical risk in the dimension of risk of bias judgments in selection of the reported result. From the six included nonrandomized studies, four had an overall classification of moderate/serious risk, while two had critical risk.

Table 5. Assessment of risk of bias in non-randomized trails included with ROBINS-I.

\begin{tabular}{|c|c|c|c|c|c|c|c|c|}
\hline Study & D1 & D2 & D3 & D4 & D5 & D6 & D7 & Overall \\
\hline [33] & & & & & & & ! & \\
\hline [6] & & & & & & & & \\
\hline [32] & & & & & & & 1 & ! \\
\hline [34] & & & & & & & ! & ! \\
\hline [36] & & & & & & & 1 & 1 \\
\hline [31] & & & & & & & ! & ! \\
\hline
\end{tabular}

D1: reaching risk of bias judgements for bias due to confounding; D2: reaching risk of bias judgments in selection of participants into the study; D3: reaching risk of bias judgments for bias in classification of interventions; D4: reaching risk of bias judgments for bias due to deviations from intended interventions; D5: reaching risk of bias judgements for bias due to missing data; D6: reaching risk of bias judgements for bias in measurement of outcomes; D7: reaching risk of bias judgments for bias in selection of the reported result; Green (+): low risk; Yellow (!): moderate/serious risk; Red: critical risk.

\subsection{Results of Individual Studies: Acute (Immediate) Effects}

The synthesis of the results regarding the acute effects of concurrent training (i.e., hormonal responses, strength and power, and internal and external loads) can be found in Table 6. 
Table 6. Qualitative synthesis and summary measures considering the acute effects of concurrent training methods.

\section{Study}

\section{Internal Load (IL)/External Load (EL)}

IL: Comparing Average sRPE (AU) for football-specific ET between groups (RT $+\mathrm{ET}, 7 \pm 1$; ET $+\mathrm{RT}, 6 \pm 1 ; \mathrm{p}=0.05$ ) showing a significant difference.

EL: Comparing total distance covered $(\mathrm{m})$ during the football specific

ETC between groups (avg. RT + ET, $5942 \pm$ 1057; ET + RT, $6213 \pm$ 958;) showing significant differences.

Study

\section{Hormonal Response}

No main effect between trails regarding Cortisol concentration $(\mathrm{mmol} / \mathrm{L})(p=0.07)$.

A moderate $\mathrm{ES}$ between conditions at time point $4(13: 45)(\mathrm{ES}=-0.95)$.

Time point $1(8: 00)$ to time point $2(9: 45)$

CT1 Cortisol $(\mathrm{mml} / \mathrm{L})$, very large effect (reduction) $(\mathrm{ES}=2.17)$

Time point 3 (12:30) to time point $4(13: 45)$ CT1 Cortisol $(\mathrm{mmol} / \mathrm{L})$, large effect (reduction) $(\mathrm{ES}=1.24)$

Time point $4(13: 45)$ to time point $5(15: 15)$ CT1 Cortisol $(\mathrm{mmol} / \mathrm{L})$, large effect (reduction) $(\mathrm{ES}=1.14)$.

Time point 3 (12:30) to time point 4 (13:45) CT1 Cortisol $(\mathrm{mmol} / \mathrm{L})$, small effect size (no change) $(\mathrm{ES}=-0.35)$.

Time point $1(8: 00)$ to time point $2(9: 45) \mathrm{CT} 2 \mathrm{Cortisol}(\mathrm{mmol} / \mathrm{L})$, large effect size (reduction) $(\mathrm{ES}=1.9)$.

Time point 4 (13:45) to point $5(15: 15)$ CT2 Cortisol $(\mathrm{mmol} / \mathrm{L})$, very large effect size (reduction) $(\mathrm{ES}=2.10)$

When compared between trails, there was no main effect observed between trails $(p=0.22)$

Between trails there was a moderate effect in time point $3(12: 30)(\mathrm{ES}=0.63)$

Between trails Testosterone AUC, there was a moderate effect $(E S=0.71)(C T 1 ; 300 \pm 76$ versus CT2; $244 \pm 81)$

No change in Testosterone $(\mathrm{mmol} / \mathrm{l})$ pre to post-training in either exercises mode $(\mathrm{S} ; \mathrm{ES}=0.04, \mathrm{E} ; \mathrm{ES}=-0.11)$

Time point 3 (12:30) to time point 4 (13:45) CT1 Testosterone (mmol/L), large effect size (reduction) $(\mathrm{ES}=1.34)(p=0.01)$

No statistical differences in growth hormone concentration (ug/L) between trails $(p=0.21)$

Between trails comparison Growth Hormone concentration (ug/L) in time point 3 showed a moderate effect $(E S=0.82)$.

Between trails comparison Growth Hormone concentration (ug/L) in time point 4 showed a moderate effect $(\mathrm{ES}=0.72)$.

Between trails comparison Growth Hormone AUC was observed (CT1; $14 \pm 11$ versus CT2; $5 \pm 9 ; \mathrm{ES}=-1.08)$.

Time point $3(12: 30)$ to time point 4 (13:45) CT1 Growth Hormone concentration (ug/L), large effect (reduction) $(\mathrm{ES}=1.38)$.

Time point 4 (13:45) to time point 5 (15:15) CT1 Growth Hormone concentration (ug/L), moderate effect (increase) $(\mathrm{ES}=-0.86)$.

Time point 4 (13:45) to time point $5(15: 15)$ CT2 Growth Hormone concentration (ug/L), large effect $(\mathrm{ES}=-1.08)$.

Time point 1 (8:00) to time point 4 (9:45) CT2 Growth Hormone concentration (ug/L), moderate effect (ES $=-0.77)$ 
Table 6. Cont.

Testosterone concentration $(\mathrm{pg} / \mathrm{mL})$ on pre $(0 \mathrm{~h}) \mathrm{SSG}+\mathrm{RT}-4.4$

(32.5) (trivial, ES = 0.07) vs. RT + SSG 17.0 (25.3) (small, ES = 0.27) Trail difference, moderate effect size (ES=0.73).

Testosterone concentration $(\mathrm{pg} / \mathrm{mL})$ on pre ( $2 \mathrm{~h}) \mathrm{SSG}+\mathrm{RT}-48.0$

(35.9) (moderate, ES = 0.89) vs. RT + SSG - 33.2 (34.3) (small,

$\mathrm{ES}=0.59)$. Trail difference, small effect size $(\mathrm{ES}=0.42)$

Testosterone concentration $(\mathrm{pg} / \mathrm{mL})$ pre $(24 \mathrm{~h}) \mathrm{SSG}+\mathrm{RT}-1.3$

(71.8) (trivial, ES $=0.02)$ vs. RT + SSG $-14.0(62.0)($ small

Cortisol concentration $(\mathrm{pg} / \mathrm{mL})$ pre $(0 \mathrm{~h}) \mathrm{SSG}+\mathrm{RT}-0.066(0.279) \quad$ Jump height $(\mathrm{cm})$ on pre $(0 \mathrm{~h}) \mathrm{SSG}+\mathrm{RT}-2.2(3.1)(\mathrm{small}, \mathrm{ES}=0.4)$ (small, ES $=0.30)$

vs RES + SSG $-0.057(0.217)$ (small, ES $=0.31)$. Trail difference trivial effect size ( $\mathrm{ES}=0.04)$

Cortisol concentration $(\mathrm{pg} / \mathrm{mL})$ pre $(2 \mathrm{~h}) \mathrm{SSG}+\mathrm{RT}-0.310(0.192)$

[31] (large, ES = 1.89)

vs RT + SSG -0.251 (0.178) (large, ES = 1.72). Trail difference small effect size $(E S=0.32)$.

Cortisol concentration (pg/mL) pre (24 h) SSG + RES -0.065 (0.208) (small, ES = 0.36)

vs RT + SSG $-0.033(0.173)$ (small, ES $=0.21)$. Trail difference trivial effect size $(\mathrm{ES}=0.17)$.

$T / C$ ratio (AU) pre (0 h) SSG + RT 102.6 (216.9) (small, ES $=0.52)$ vs RT + SSG $112.9(115.0)$ (moderate, ES $=0.73)$. Trail difference, trivial (moct

vs. RT + SSG -4.1 (2.6) (moderate, ES $=0.67)$. Trail difference -1.9 (3.3), moderate effect size $(E S=0.68)$.

Jump height $(\mathrm{cm})$ pre $(24 \mathrm{~h})$ SSG + RT $-2.6(4.9)($ small, ES $=0.49)$

vs. RT + SSG $-1.3(2.0)$ (small, ES = 0.25). Trail difference $1.2(5.4)$ there is a small effect size $(E S=0.33)$.

$\mathrm{CMJ}$ relative $\mathrm{PPO}(\mathrm{W} / \mathrm{kg})$ on pre $(0 \mathrm{~h}) \mathrm{SSG}+\mathrm{RT}-0.84(2.75)$

(trivial, ES =0.12) vs. RT + SSG -3.53 (2.48) (small, ES = 0.5). Trai difference -2.69 (3.30) moderate effect size $(E S=1.03)$.

CMJ relative PPO $(\mathrm{W} / \mathrm{kg})$ on pre $(24 \mathrm{~h}) \mathrm{SSG}+\mathrm{RT}-1.95(3.81)$ (small, ES = 0.31) vs. RT + SSG -1.56 (2.30) (small, ES $=0.25$. Trail difference $-0.37(4.19)$ trivial effect size $(E S=0.12)$.
IL: Mood score (AU) in the SSG + RT pre (0 h) 8.6 (9.1) AU, moderate effect size (ES = 0.72) and pre $(24 \mathrm{~h}) 5.3$ (11.1) AU small effect size $(\mathrm{ES}=0.44)$

Mood score (AU) the RT + SSG pre (0 h) 3.2 (11.4) AU, small effect size $(\mathrm{ES}=0.24)$ and pre $(24 \mathrm{~h}) 4.0(8.5) \mathrm{AU}$, small effect size $(0.29)$ Mood score (AU) RT + SSG vs SSG + RT pre $(0 \mathrm{~h})$, there is a small effect size $(E S=0.52)$ Mood score (AU) in the

$\mathrm{RT}+\mathrm{SSG}$ vs SSG + RES pre $(24 \mathrm{~h})$, trivial effect size $(\mathrm{ES}=0.14)$ RPE score (AU) between groups (SSG + RT, $7.3 \pm 1.0 \mathrm{AU}$; RT + SSG,7.6 $1.1 \mathrm{AU})$, there were similar measurements.

EL: Player total distance $(\mathrm{m})$ between groups (SSG + RT, $4659 \pm$ $611 \mathrm{~m}$;RTS + SSG, $4660 \pm 583 \mathrm{~m}$ ), there were similar measurements Players High speed running distance $(\mathrm{m})$ between groups SSG

$+\mathrm{RT}, 65 \pm 16 \mathrm{~m}$; RES + SSG,58 $\pm 13 \mathrm{~m}$ ) there were simila measurements.

PlayerloadTM (AU) between group (SSG + RT, $470 \pm 72 \mathrm{AU}$; RT + $\mathrm{SSG}, 465 \pm 75 \mathrm{AU})$, there were similar measurements.

$\mathrm{T} / \mathrm{C}$ ratio (AU) pre (2 h) SSG + RT 322.1 (237.7) (large, ES = 1.73)

vs RES + SSG 261.8 (232.4) (large, ES = 1.41). Trail difference small effect size $(\mathrm{ES}=0.26)$.

$\mathrm{T} / \mathrm{C}$ ratio (AU) pre (24 h) SSG + RT 35.7 (117.7) (small, ES = 0.35)

vs RES + SSG -11.0 (98.6) (trivial, ES = 0.10). Trail difference, small effect size $(E S=0.43)$.

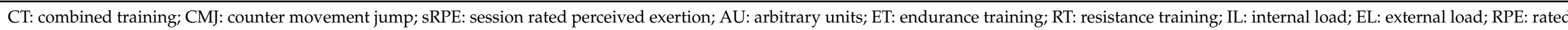
perceived exertion; SSG: small sided games; T/C: testosterone/cortisol; PPO: peak power output. 
Two of the included studies [31,32] tested athletes' hormonal responses in regard to CT modality order. Both studies reported no main effects of testosterone (T) or cortisol (C) between conditions. In another study [32], the researchers observed changes in T and C typical of that observed in the diurnal fluctuations in the absence of exercise; no significant changes were observed between trials. Only human growth hormone (hGH) had different responses between trials, showing an increase in one trial but decreasing in the other. As mentioned by the authors, this could be because the trial in which hGH decreased also had a shorter rest period between bouts (60 min vs. $105 \mathrm{~min}$ ). The dietary strategy employed was also different regarding the absence of carbs, while also contributing to this result.

Other researchers [31] reported the same finding regarding differences between groups, with the exception of T immediately after the training bout of RT. T had a moderate and significant effect between CT trials, favoring RT, followed by endurance, which was also speculated on by [32] (though this expected finding did not present itself). Since [32] was carried out at 17:30 or 20:30, RT training could also have disrupted the normal circadian rhythm, which could have led to the potentiation of the following training session [37].

In [31], jump height $(\mathrm{JH})$ and relative peak power output (PPO) were measured. Athletes' performance in both measures decreased. JH decreased by -2.2 (3.1) in the SSG + RES condition and by -4.1 (2.6), with no significant difference between protocols $(p=0.052)$. PPO followed the same trend (JH, SSG + RES - 0.84 (2.75) vs. RES + SSG -3.53 $(2.48))$, with no significant differences between protocols $(p=0.009)$. Both measures were taken immediately after the first training bout.

Concerning specific performance measurements/external load during soccer-specific training, only two studies [6,31] employed tests with opposing results. In [6], a significant difference in total distance covered was observed between groups (ET + RT 6213 (958) vs. RT + ET 5942 (1057)). Additionally, HRmax (min) favored the ET + RT 11(2) group (vs. RT + ET 5 (12)), suggesting that players ran more often and at a higher intensity when ET was performed first.

On the other hand, [31] found no significant differences between groups when considering total distance, HSR distance, and PlayerLoadTM when dietary intake was controlled and equated for both groups. Although HRmax (min) and HSR distance $(\mathrm{m})$ are not the same, both have been used to measure "quantity" and indicate training intensity [38].

The same studies above considered internal load. Contrary to external load, both studies found no significant differences between groups. It is unknown whether this is a consequence of the significantly lower external load, as mentioned above. Nevertheless, when ET was performed first, and when more running was performed at a higher intensity, players still went through an RT program with 4RM-2RM, and this near-failure task did not affect either RPE measurement.

It is also interesting that the avg. sRPE and RPE have maximum scores of 7 and 6, respectively, for a near failure task in a couple of sets, out of the ordinary, but ending up with an insignificant difference in avg. sRPE and RPE between training orders. The same happened in [31], where the RPE score was higher (see Table 4), although no difference was found when the training order was switched.

\subsection{Results of Individual Studies: Chronic (Adaptations) Effects}

The synthesis of the results regarding the effects of concurrent training on fitness dimensions (strength and power, muscle architecture, aerobics, sprinting, jumping, changeof-direction, and repeated sprint ability) can be found in Table 7. 
Table 7. Qualitative synthesis and summary measures considering the chronic effects of concurrent training methods.

\begin{tabular}{|c|c|c|c|c|c|c|c|}
\hline Study & Strength and Power & Muscle Architecture & Aerobic & Sprinting & Jumping & COD & RSA \\
\hline [33] & 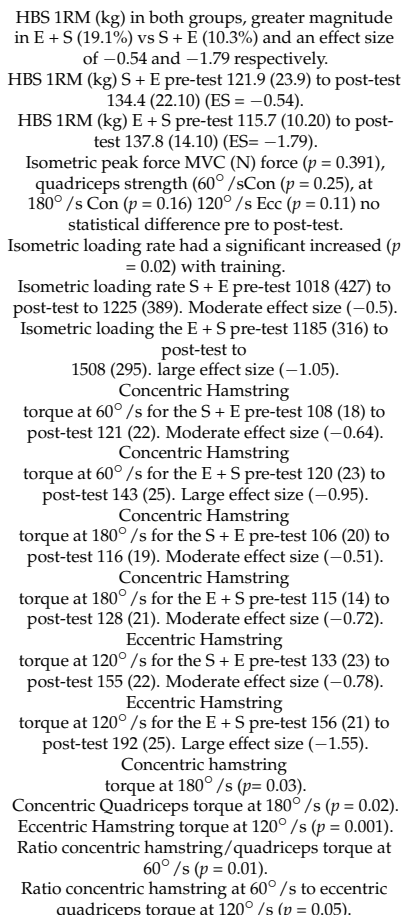 & 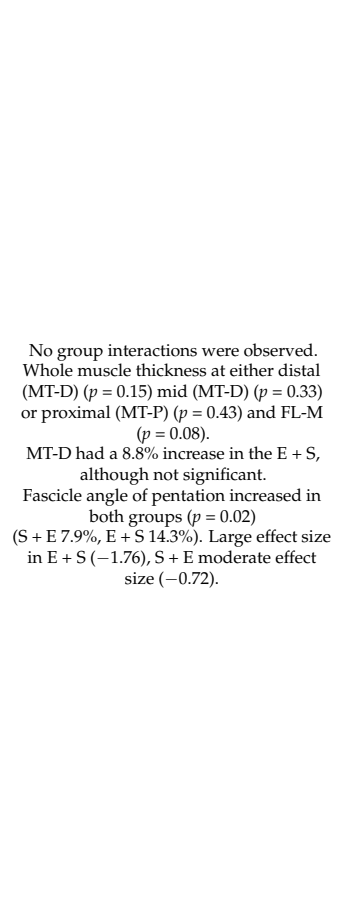 & & 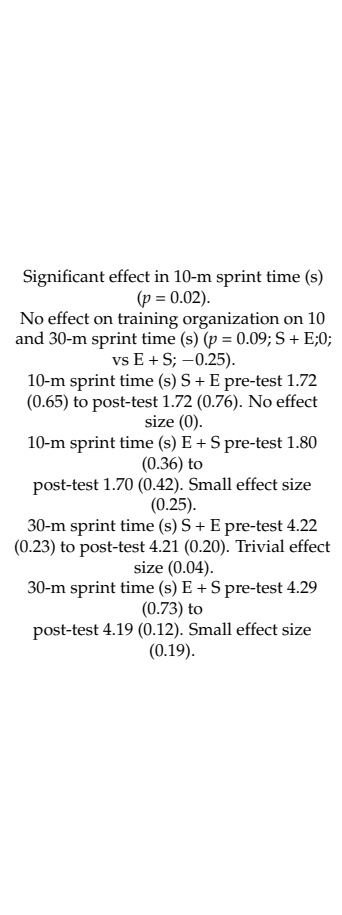 & 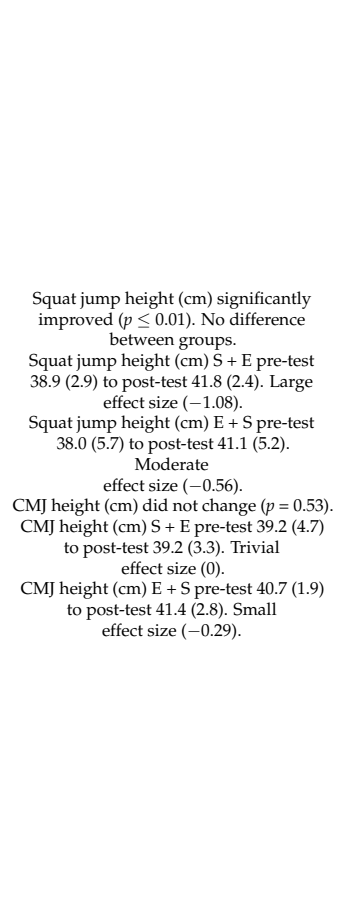 & - & - \\
\hline
\end{tabular}


Table 7. Cont

\begin{tabular}{|c|c|c|c|c|c|c|c|}
\hline Study & Strength and Power & Muscle Architecture & Aerobic & Sprinting & Jumping & COD & RSA \\
\hline [34] & - & - & - & 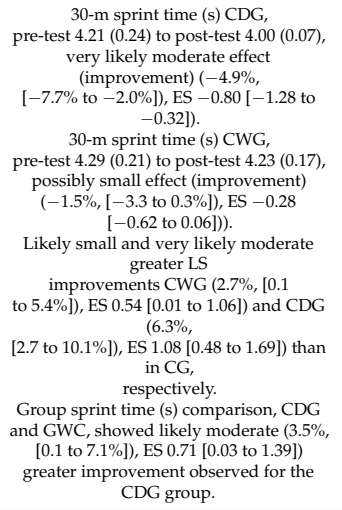 & - & 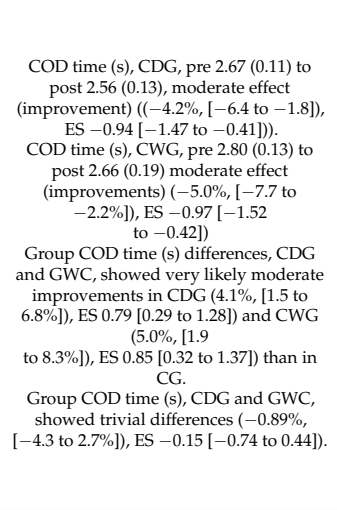 & 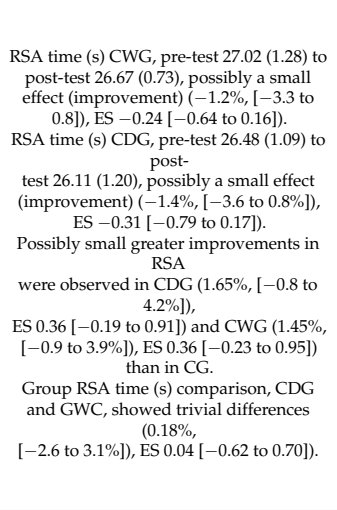 \\
\hline [7] & 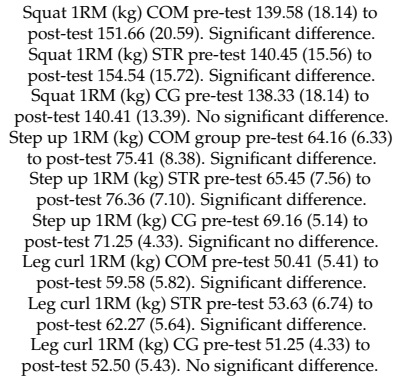 & - & & 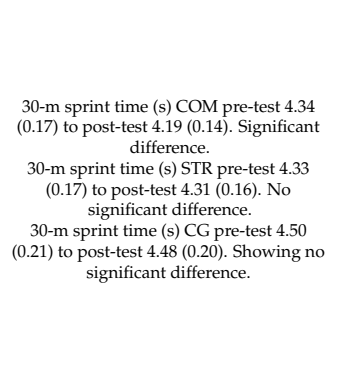 & 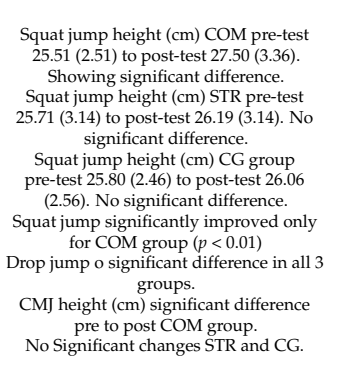 & & - \\
\hline
\end{tabular}


Table 7. Cont.

\begin{tabular}{|c|c|c|c|c|c|c|c|}
\hline Study & Strength and Power & Muscle Architecture & Aerobic & Sprinting & Jumping & COD & RSA \\
\hline [35] & 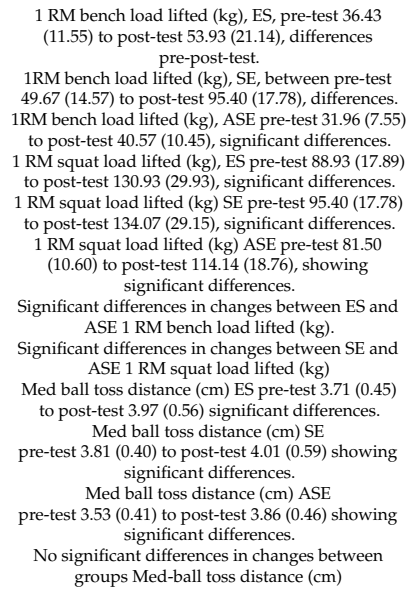 & - & 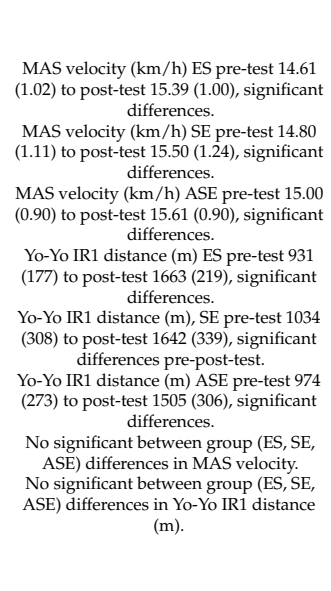 & 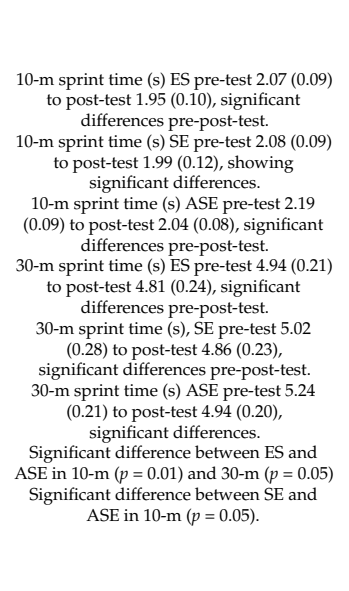 & 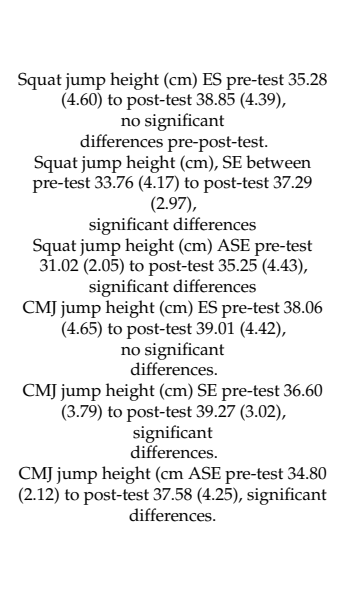 & 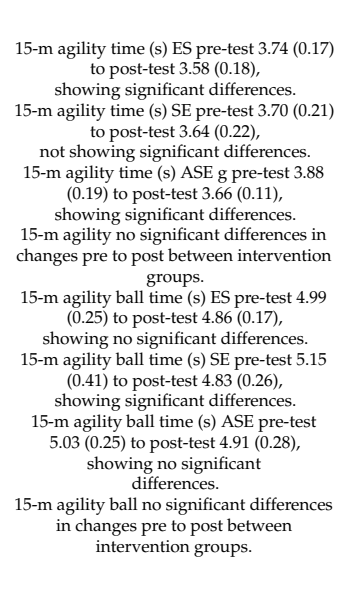 & - \\
\hline [36] & 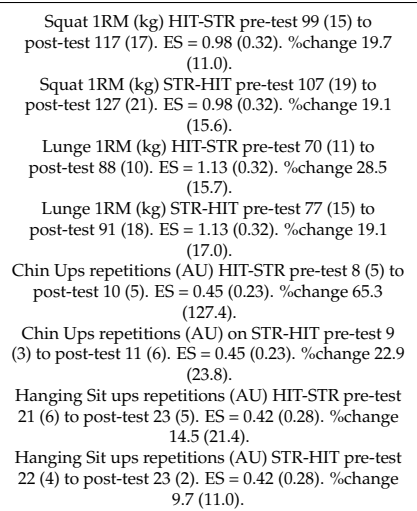 & - & 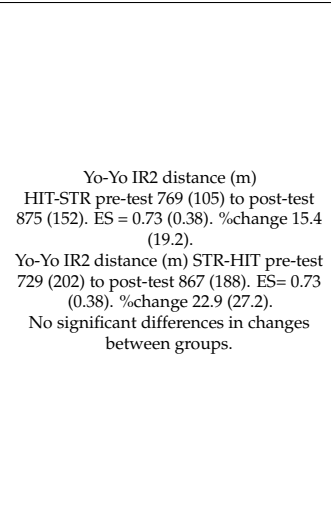 & 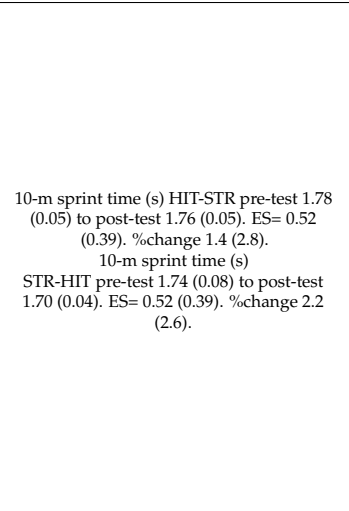 & 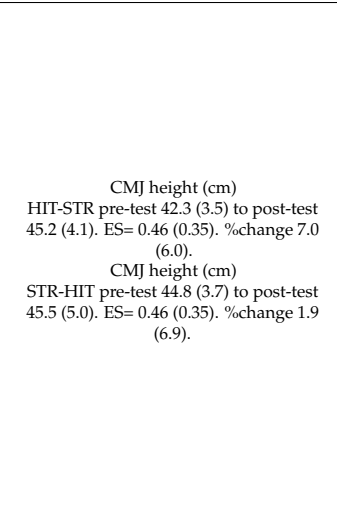 & 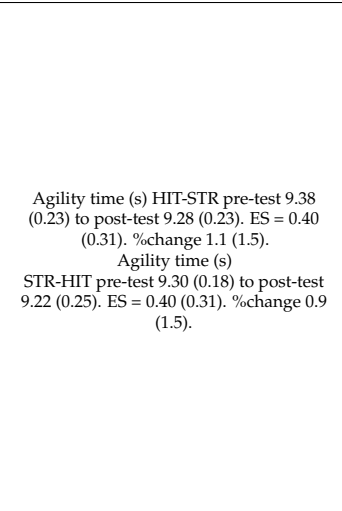 & 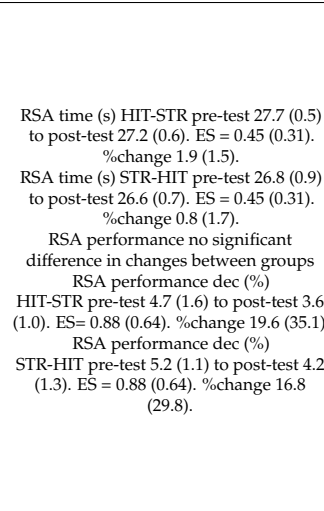 \\
\hline
\end{tabular}

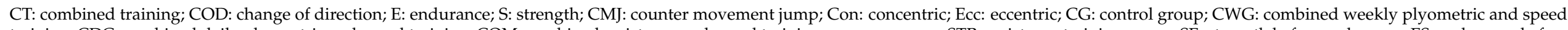

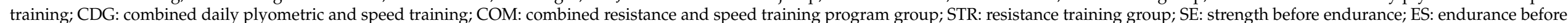

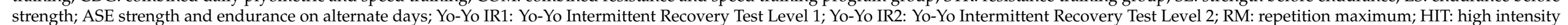
training; RSA: repeated sprint ability; HBS: Half back squat; MT-D: Muscle thickness (Distal); MT-P: Muscle thickness (proximal); FL-M: Fascicule Length (Mid); MAS: maximal aerobic speed. 
Only one study [33] reported changes in muscle architecture. Although neither group exhibited significant differences pre- to post-test or between groups regarding muscle thickness, the $\mathrm{S}+\mathrm{E}$ had a $1 \%$ increase at the distal location, while $\mathrm{E}+\mathrm{S}$ had an $8.8 \%$ increase. This seems contradictory at first since, in theory, the players in this group would perform $S$ in a more fatigued state, possibly limiting their training volume, which is linked to muscle hypertrophy [39] (S + E; $13443 \pm 2485 ; \mathrm{E}+\mathrm{S} ; 12341 \pm 1574)$. Interestingly, and contrary to [40] and as mentioned above, this was not the case, leading to another possible explanation.

Significant increases $(p=0.02)$ in pennation angle were also found in both groups, again favoring the E + S group (S + E 7.9\% vs. E + S $14.3 \%$ ), with a large effect for the E + S group. It is unclear whether this difference in pennation angle was due to training order or nutrition (or both), as there are many confounding factors. Nevertheless, we can speculate that training order, in addition to nutrition, impacts how muscles adapt.

Four of the studies included in this review address strength and/or power measurements $[7,33,35,36]$. Lower body strength was measured by 1 RM back squat (1RM BS) in all four studies, with mixed results. For example, [36] reported similar improvements in 1RM BS (HIT-STR $19.7 \%$ vs. STR-HIT 19.1\%), whereas [33] did not (E + S 19.1\% vs. S + E $10.3 \%)$. In [35] also, no significant differences were reported between the SE and ES groups' changes in 1RM BS and Bench. Interestingly, the ASE group had fewer gains in 1RM BS than the SE group, but not the ES; conversely, the ASE group had fewer gains in 1RM Bench than the ES group, but not the SE group.

Multiple factors affect strength [41], more specifically, in dynamic exercises, such as the back squat, compared to isometric exercises, due to technical factors. Regarding power development, [33] presented no significant differences in changes regarding IMVC-LR (E + S $27 \%$ vs. S + E 20\%) though larger effects were imposed on the E + S group. The study of [35] also found no significant differences in changes between groups regarding med ball toss performance. The findings in [33] regarding IMVC-LR could be explained by a combination of reasons, similar to those presented for muscle thickness and pennation angle.

When it comes to upper body strength and power, the results showed no differences in training order, except for the ASE group. However, considering that athletes' age and PHV were not determined, there might be a question about maturation within the group, or other factors, since the SE and ES groups were similar. Thus, if there was a case for better adaptation, this would probably alternate between RT and endurance. Moreover, power did not differ in this study when comparing med ball toss scores.

Two studies included in this article $[35,36]$ measured outcomes related to aerobic metrics. Both studies employed the Yo-Yo Intermittent Recovery Test (YYIRT), either at level 1 or 2 . In both studies, athletes were able to achieve significant improvements in YYIRT distance pre- to post-test. Furthermore, no significant differences in changes between groups were found in either study. In [35], improvements in the YYIRT1 between $79 \%$ and $54.4 \%$ were found for the intervention groups. Interesting also was the fact that the control group in this study exhibited a $42 \%$ improvement in the same test.

Of all the studies included, four $[7,33,35,36]$ tested for some type of jumping ability. A clear trend emerged in all the studies that included a squat jump (SJ) and a countermovement jump (CMJ) (i.e., the intervention groups), independent of training order, for participants who were not exposed to any type of high-intensity plyometric activity (including speed work). These participants did not experience any significant pre- to post-intervention increases in CMJ (see Table 5). Even when RFD (IMVC-LR) increased, such as in [33], it was able to increase SJ. There are a few possible reasons for this. For one, all athletes in the studies in which no type of high-intensity plyometric activity was employed were considerably strong at baseline (1 RM BS or IMVC-PF measures); therefore, strength was not a limiting factor in jumping performance for these athletes.

Sprinting tends to follow the same thought processes as jumping, with the exception of [33], where the intervention group only had traditional resistance training [7] (STR group), which seemed to be an insufficient stimulus, or the correct type of training in order 
to increase sprint ability at either $10-\mathrm{m}$ or $30-\mathrm{m}$. It seems that athletes can improve sprint performance through strength training [42], but only to a certain point $[43,44]$. The changes in sprint performance observed by Enright [33] could be due to changes in pennation angle [45].

Three of the studies [34-36] evaluated agility or change-of-direction. All interventions improved change-of-direction ability pre- to post-training. No differences were found between groups, with the exception of the SE group in the study of Makhlouf [35]. In this study, ES improved by around $4.2 \%$ in both cases. Alternated strength and endurance (ASE) improved by about $5.6 \%$, while the SE group improved by only $1.6 \%$, indicating a significant difference in changes between groups.

This difference between the SE and ES groups is interesting since children have a more generalized response to training stimulus than adults [35]. However, the SE group only improved by $1.6 \%$ in a 12 -week study, which is close to what was observed in [36] (HIT-STR $1.1 \%(1.5)$ vs. STR-HIT 0.9\% (1.5)). However, [8] included adults and lasted just five weeks after de-training. A possible explanation for this could be that [35] did not include any tests for participants' maturation status, which could have affected their baseline performance metrics and their responses to the training stimuli $[46,47]$. On the other hand, none of the other tests that account for strength, power, and speed showed any significant differences pre- or post-intervention when comparing the ES and SE groups. Thus, there is no clear explanation for these results.

Another interesting fact was that in [34], interventions did not use resistance trainingonly plyometric and speed training (linear sprints and COD drills) were performed-but still achieved similar results (CDG $4.2 \%$ vs. CWG 5.0\%) as in [35], with an older population ( $\sim 17$ years). These results could be explained by the fact that plyometric training can increase an athlete's ability to utilize the stretch-shortening cycle [48], which might impact COD ability [49].

Two studies $[35,36]$ reported changes in RSA performance1 with no significant differences in changes between groups. Both studies showed similar results regarding improved RSA ability using two different training strategies, which probably caused some differences in training adaptations that contribute to RSA performance.

In the intervention in [34], the mechanisms which most likely enhanced RSA ability were increased running economy due to plyometric work [50], which reduces the amount of energy used per set and, consequently, leaves the athlete with more energy available for the next one. The other mechanism that improved RSA was the increase in the 30-m sprints due to sprint work (not negating the fact that plyometrics also contribute to sprint performance).

In [51], the most robust predictor of RSA was anaerobic power, which is, for example, the fastest individual's sprint time. Therefore, the combination of these factors led to an increased RSA for [34]. On the other hand, [36] employed a combination of strength and power training, resistance training, and plyometrics while also employing HIT training. Although the 10-m sprint time improved, this did not necessarily translate to an improvement in 30-m sprint time due to differences in kinetics and kinematics. The degree to which this might influence RSA is probably less than in [34].

\section{Discussion}

This systematic review presents the main effects of combined training normally used in a soccer context, either in acute responses or chronic adaptations. It also investigated whether the order of the training modality affects any responses to the stimulus.

\subsection{Discussion of Evidence: Acute Effects}

\subsubsection{Hormonal Responses}

Two studies [31,32] found no significant changes in either testosterone (T) or cortisol (C), with the exception of T immediately after RT training in [31]. Short-term changes in $\mathrm{T}$ can enhance the performance capacity of the neuromuscular system, such as second messenger and lipid/protein pathways, behavior and cognition, motor system, energy 
metabolism, and muscle properties [52], in combination with post-activation potentiation (PAP) [53], which is the enhancement of muscle force and muscle rate force development (RFD) [44,45] using high-loads [54]. For example, in RT, increased performance may be observed [37] in the following training bout, as mentioned above.

Overall, $\mathrm{T}$ and $\mathrm{C}$ did not show any main differences between studies and trials, with the exception of [31], immediately after the strength training (although the same was also expected in [32]). The ability of $\mathrm{T}$ to disrupt the normal circadian rhythm may have potential use in a normal training scenario to potentiate specific soccer training for teams who have late-night training sessions or even when travelling for those who are suffering from jet lag. This is possible because $\mathrm{T}$ can enhance neuromuscular force-generating properties [52] and training motivation [55].

To the best of the authors' knowledge, there are no guidelines for what minimum dosage of RT can be used to increase T without imposing excessive fatigue. In [37], players completed three sets of 3RM for bench press and squat. Although the volume was low, the intensity was high in close proximity to failure, and players were able to recover and still get the benefit of increased $\mathrm{T}$ and possibly PAP. Players were trained and strong (lifting approximately $1.5 \times \mathrm{BW}$ and almost $2 \times \mathrm{BW}$ in bench and squat for three reps), and their baseline strength might have an influence on the prediction of free-ton training performance [56]. Their training experience might also have a role in the training intensity and volume needed to raise $\mathrm{T}$ and still recover in time for the following session. Finally, it would be interesting if an upper body session only could affect $T$ release and still potentiate the lower body performance by PAP and T release, or even both.

\subsubsection{Strength and Power}

Regarding], both groups decreased their jumping ability and power-related characteristics [31]. These changes could be explained by the near proximity to failure of the RT exercises, and one principle of PAP is that the exercises imposed should not cause fatigue [54], which has possibly not the case when we consider the close proximity to failure. Additionally, this could also be explained as task-dependency fatigue [31]. Nevertheless, there were no significant differences between groups immediately after, or $24 \mathrm{~h}$ after, the first training bout.

If the RT training was not as hard, being near failure, or the time between the end of the RT training and testing was longer, perhaps the observed decreases would be lowered or potentiated. Therefore, it is plausible that volume and intensity at which loading is imposed plays a bigger role when there is less time between sessions regarding the impact on the performance of athletes following a training session.

\subsubsection{External Load}

Two studies [6,31] found contradictory results in terms of external load measurements. However, the ET + RT group had consumed a total of $1.25 \mathrm{~g} / \mathrm{kg}$ of carbohydrates after finishing RT training, $0.45 \mathrm{~g} / \mathrm{kg}$ of this before the first bout (ET). This was contrary to the RT + ET group, who consumed the $0.45 \mathrm{~g} / \mathrm{kg}$ of carbohydrates before ET but had already completed the RT. The observed difference affects running performance [57], probably HRmax, to a higher degree due to its dependency on carbohydrates [40,41]. Meanwhile, in [31], dietary intake was controlled in both trials, and players received the same amount of carbohydrates in between training bouts, which could have led to the differences in the results. It is unknown also whether the pitch size and/or exercise demands were adjusted because players had engaged in a previous RT training. Finally, 17 CT sessions were performed during the 10-week study, 11 of which were performed in weeks 1-3, representing $65.6 \%$ of total volume performed (weeks $1-3$ had a significantly higher total volume than weeks $4-10(p=0.04))$, possibly indicating that total volume may play a role when accounting for interference with soccer-specific performance in training.

When food intake was equalized between trials, no significant differences were shown, not only for high-intensity efforts but also for total distance covered. Furthermore, Player- 
Load, although not included in [6], can also indicate intensity by including acceleration and decelerations. From an RT perspective, both studies are not that different. In [6], players lifted between 4RM and 12RM. Unfortunately, it is not described whether these were the true RMs, taken up to failure. Nevertheless, in [31], volumes were extremely high in the first weeks (1-3), which is a proxy for fatigue, although the volume was possibly lower due to the RT program repetition scheme $(4 \times 4)$. At least in the squat, sets were taken to near failure, which is another proxy for fatigue. Rest time between bouts was also probably not a very significant differentiator [31] $120^{\prime}$ vs. [6] 75 (48).

To summarize, although both studies have different outcomes, the volumes implemented in [6] in weeks 1-3 might have influenced the external load in the two trials. Therefore, it would be interesting to know the pitch sizes and details of the exercisesspecifically, whether they were less intense on the days that RT training was employed before ET, as this would have changed the external load outcomes. In [31], no differences were shown for external load or jumping ability, although jump height might fully explain fatigue [58]; if it really was extended to a large extent, probably significant differences could be seen.

\subsubsection{Internal Load}

Two studies [6,31] measured the impact of the training order of CT training, with differing results. Internal load is the way that the body responds to the external load imposed on athletes. The external load in [6] was extremely high in the first three weeks compared to [31]. This could have impacted internal load indicators such as RPE, creating a significant difference in one study [6] but not the other [31]. RPE scores do not follow up with the training employed, at least in RT, or soccer-specific training was too light to equate to these average RPE, or players were not sufficiently familiarized with the process, bringing the validity of the data into question. Finally, one study only took two interventions [31], while the other involved 17 [31], which leaves more room for other confounding factors (e.g., weather and other psychophysiological factors) to affect the perception of effort/internal load, influencing the athletes' responses to the stimulus [28] to a greater degree for Enright [6] than Sparkes [31]. Future research using RPE with GPS data based on RSImod or RSI data instead of jump height alone would be interesting.

\subsection{Discussion of Evidence: Adaptations}

\subsubsection{Muscle Architecture}

In study of Enright et al. [33], no significant intra- or inter-group pre- to post-intervention differences were found, but there was a difference regarding muscle pennation angle.

As seen in subSection 4.1.3, nutrition also has an important role, and the $\mathrm{E}+\mathrm{S}$ group consumed more key nutrients (carbs and protein) [6] between training bouts. More specifically, the S + E group only consumed protein between workouts. It is known that, together with AMPK and SIRT1, ER stress leads to mTORC1 inhibition. This could be caused by high lipid exposure and glycose deprivation [24]. In this way, the S + E group could have been exposed to a less positive muscle protein balance, therefore blunting the potential for muscle hypertrophy.

One study [59] suggests that, when performing concurrent training on the same day, the order and recovery time between strength and endurance can influence acute signaling responses. Thus, in the $\mathrm{S}+\mathrm{E}$ group, the anabolic signaling mTOR could be blocked later by the signaling caused by endurance training via the AMPK/SIRT-1 pathway, thereby limiting this cascade of events that promotes strength-related adaptations, including adaptations in pennation angle.

In summary, nutrition has a key role in supporting muscle adaptations caused by training stimuli. When it comes to increasing muscle thickness, it is recommended that athletes consume carbohydrates before a workout and protein afterward to maximize muscle hypertrophy [60]. If training endurance is implemented after resistance training, athletes are recommended to consume carbohydrates to prevent muscle loss catabolism [61]. 
If possible, although it is not a reality for all teams, the ideal scenario would be to separate endurance from resistance training by six hours to maximize gains in muscle hypertrophy [21]. When this is not possible, the best alternative would be to perform strength training after endurance training, because endurance is a limiting factor for strength but not the other way around [62].

\subsubsection{Strength and Power}

Mixed results appear when comparing the results of the studies that addressed strength and power. Muscle hypertrophy affects strength outcomes [63]. In study of Enright et al. [33], as seen above, E+S had more muscle hypertrophy, which could be the cause of the difference in 1RM BS. In the same study, IMVC-PF had no significant difference changes between groups or pre- to post-intervention. Thus, the increases in 1RM BS were also probably due to improvements in technical proficiency in the movement rather than neural adaptations to a large degree, probably due to the training program repetition scheme, which is more for muscular adaptations than neuromuscular, and because they were already strong athletes considering their bodyweight-to-force, expressed in the squat and IMVC-PF. Therefore, the margin for progression is low.

Overall, based on the studies in this review, it looks like there is no significant difference in training order regarding strength and endurance, with the exception of [33] in the $1 \mathrm{RM} B S$, but not in the isometric test, with no technical factor associated with the exercise. These differences could be due to other factors (mentioned in the previous chapter) that have an impact on muscle hypertrophy and with no significant effect of neural adaptations regarding strength outcomes. According to [20], strength and hypertrophy are not as susceptible as power development to decreases during concurrent training.

It is well-established that fiber type affects muscle contractile velocity [64]. It is also possible to increase fast-twitch muscle fibers with strength and concurrent training, as shown in [62], as the strength alone group had a bigger shift in fast-twitch compared to the concurrent group. Thus, if the overall muscle thickness was greater in the $\mathrm{E}+\mathrm{S}$ group to a certain degree, it can be speculated that the shift or hypertrophy, or a combination of both, regarding fast-twitch muscle fibers had a greater effect. This, along with a greater pennation angle, which is associated with muscular strength [33], caused a bigger slope in the IMVC-LR for the $\mathrm{E}+\mathrm{S}$ group.

It is known that the upper body is not affected to the same degree as the lower body when it comes to concurrent training, especially in soccer, where the lower body is utilized the most during training [60].

It would be interesting to investigate a situation where training protocols are similar in terms of timing of interventions and nutritional intake. Although it is invasive and expensive, analyzing fiber type shifts and hypertrophy would help to explain some training outcomes and guide the order of training modalities.

It looks as if, when athletes are strong enough, increases in $\mathrm{kg}$ to a specific movement can be due to technical proficiency to a larger degree than neuromuscular adaptations, which is the end goal. So, if possible, a combination of isometric type testing and dynamic exercise could be employed to understand if the stimulus imposed by the dynamic exercise is really provoking the desired adaptations (neural activation).

Finally, when it comes to concurrent speed and strength, strength gains do not seem to be affected as shown in [7], probably because speed training is non-fattening training that is generally performed with low volumes and total rest between sets. Therefore, the mechanisms by which endurance affects strength are not present in speed training.

\subsubsection{Aerobic}

The training interventions in both studies $[35,36]$ were effective for creating positive adaptions in aerobic power and capacity. This finding is in line with the findings of [65] which showed that SSGs are able to improve cardiovascular performance in adult soccer players. However, because the group in this study were young athletes, their potential 
to improve is even bigger, possibly enhancing the effects of training intervention. In fact, improvements in [36] were much lower (avg. 19.4 (23.4) than in the previous study, and the fact that this study started at the beginning of the pre-season could mean that players were de-trained and more likely to improve. The duration of [35] was 12 weeks vs. five weeks for [36], allowing less time for players to improve further. It would also be interesting if [35] had tested for athletes' maturation state, since this can affect performance in various ways and, directly or indirectly, affect running performance when comparing results from pre-puberty athletes to post-puberty athletes.

Finally, independent of the study, players improved when they supplemented their regular soccer training with high-intensity endurance training and strength training on the same day. The modality order too did not seem to affect training outcomes, with the exception that alternating days between endurance and strength instead of doing it all in the same session does not seem to have any additional benefit.

\subsubsection{Jumping}

Studies $[7,33,35,36]$ reported a combination of results varying from no improvements in various forms of jumping (SJ and CMJ) to improvements in only one (SJ) or both. In fact, studies have shown that, among well-trained athletes, strength training did not increase vertical jump performance $[66,67]$. Another reason might be the lack of exposure to a stretch-shortening cycle, such as with sprinting or jumping in $[7,36]$, where athletes were exposed to sprints, which is a plyometric activity. CMJ increased only in the SE and ASE groups, perhaps due to fatigue, as workouts were separated by only $15 \mathrm{~min}$, and endurance in the ES group could have limited the participants' neuromuscular abilities. Maturation might yet again also be a factor for adaption in young athletes, such as in the previous study. These factors, either isolated or combined, were observed in $[33,35]$, where only strength and endurance were employed, in [7], where STR and Con groups did not exhibit improvements in CMJ, and in [36], where the strength training included plyometric activities and power exercises. The only study where significant differences regarding training order were found was [35], which is contradictory, since children have more generalized responses to training than adults and recover more quickly $[68,69]$.

Due to different endurance training intensities and volumes of rest time between sessions, the results differed. However, it is plausible that there is a preference for plyometric activities, to be performed before endurance so that there is no neural or peripheric fatigue during this type of training. The choice of whether to perform strength or speed exercises before or after plyometric activity also depends on the dose, as strength can serve as PAP (if not taken to failure), or can increase fatigue (if done in proximity to failure or at high volumes), or a combination of both.

\subsubsection{Sprinting}

In general, the included studies have shown that it is possible to improve sprint performance with CT training, but with a caveat. Studies $[43,44]$ show that strength training alone is not able to increase sprint performance in high-level athletes. Strength levels are probably not the limiting factor in sprint performance, such as in $[7,33]$, as measured by the ratio of 1 RM BS and IMVC-PF to bodyweight. The difference in the study by Enright [33] is that athletes showed improvements in pennation angle that could have influenced their sprint performance [45]. When pairing endurance with strength training, there was also a slightly more positive tendency for the STR-HIT group to increase 10-m sprint performance [8]. This seems logical, since strength training in this study comprised Olympic movements, plyometrics, traditional RT, and other types of athletic movements that were performed with no or less fatigue compared to their counterparts (HIT-STR), thus enhancing the capacity to express higher levels of force at higher speeds and having a small but increased transference to the 10-m sprint than in the other group (HIT-STR).

Contradictory findings were presented in [35] compared to what is described in the literature, first because children have more generalized adaptations and, second, because 
the differences in changes between groups were significant, which should not be attributed to training organization but to other factors, such as maturation. Overall, the ASE group was the one with the fewest improvements, which also goes against [21], which states that, the more dispersed the training stimuli, the less likely it is that interference will occur, and that overall fatigue will increase from one training bout to another, potentiating the strength work by potentiating the expression of force during slow and fast velocity movements included in the training program.

When it comes to combining plyometrics and speed training, such as in [34], there is a slight tendency for better improvement when both modalities are performed on the same day. This could be due to the PAP effect, and the same criteria should be applied as in jumping.

The biggest improvement in the 30-m sprint was observed in [34]. This study also presented the fastest baseline 30-m time, leaving less room for improvement. It was also this study that combined plyometrics and speed training. This could reinforce the idea that, the more specialized the athlete is and the greater their overall level and training experience, the more specific training has to be done to improve the desired physical quality or ability. In the control group in [7], no changes were observed in sprint performance, which is in line with the literature which states that specific soccer training is enough to maintain sprint performance but that, to increase it, supplemental work should be employed.

Finally, when implementing strength training using only RT exercises that focus on the development of maximum strength without exploring other parts of the strength curve (whether from Olympics lifts, plyometrics, specific speed training, or a combination of all these), improvements in sprints can be marginal depending on the athlete's fitness level.

\subsubsection{Change-of-Direction}

In general, athletes were able to improve their COD ability with no differences observed between groups. Plyometric training and speed training can improve the rate of force development and overall power characteristics [70] that can have an impact on COD ability $[49,70]$. This, together with more specific training, i.e., practicing the COD itself, as has been done in this study, can have a significant impact on COD ability.

The least improvement regarding COD/agility metrics was that in [36], which also had the oldest (and probably more experienced) training group, although it used a mix of the methods employed in the other two studies (strength, plyometrics, and power movements). It was also the shortest study (five weeks), leaving little time to improve. It is possible that, as training age increases, more specific training must be performed in order for an athlete to progress $[36,46]$. The fact that strength has increased significantly $(1 \mathrm{RM}$ Squat, 1RM Lunge) could affect power and RFD [16], but that did not significantly transfer to their COD ability, which could lead to the belief that some types of COD drill could be beneficial. Since age is higher, a larger interference effect could be expected, decreasing training adaptations, especially on explosive strength-related parameters $[40,61]$ when compared to other younger study cohorts.

Firstly, all of the studies employed a different combination of training modalities (plyometrics and speed or strength and endurance). Training ages were different, and so were the tests used to access change of direction or agility, which makes it harder to obtain a final conclusion. It would be interesting to see strength values in [34] and compare them to the other two. Not measuring the maturation status also has a downside, because maturation can have a big influence on increases in performance [47]. For future investigations, COD deficits could be measured more precisely to access changes in COD ability and, if standardized, would simplify compressions between studies.

Finally, a mix of strength, plyometric, and specific COD drills would be a good combination to increase COD abilities, increasing the volume of more specific drills as training age increases, but not using just one modality exclusively, framing the training program according to age, maturation status, and seasonal calendar. The same should occur for time between sessions, mainly for endurance and explosive strength-related 
training, as the higher the training status, the more separated training sessions should be. In this way, the muscle force adaptations we are trying to impose that can affect COD ability (RFD, power, etc.) are decreased to a lesser degree when concurrent training is imposed. Even in youngsters, where interference might not be a problem, as mentioned above, COD also has a technical component, and learning or perfecting a skill in a fatigued state might also not indicate the best order to maximize learning.

\subsubsection{Repeated Sprint Ability}

When it comes to repeated sprint ability, two studies [34,36] showed no significant differences in either training order regarding HIT or strength. Plyometrics and speed work are also done in the same or separate sessions. Therefore, since plyometrics were utilized, running economy might be the common factor between both studies, while cardiovascular adaptations are probably not. Even though the players in [34] still endured soccer practice, this was not enough to increase RSA performance since the control group only had a $0.2 \%$ difference in RSA. In general, HIT interventions have proven to be beneficial for improving cardiovascular parameters, mainly aerobic power [71]. YYIRT 2 performance is closely linked to an individual's aerobic system [72]. In this study also, the HIT training followed the guidelines recommended by [73]. Thus, it seems plausible that the improvement in YYIRT 2 observed in [36] (see Table 3) could be the mechanism by each. RSA times also improved in this same study.

It would be interesting if both studies employed an eccentric utilization ratio or reactive strength index, or if both evaluated increases in the stretch-shortening cycle. This way, we could be sure if there was an increase in the SSC and more certain about running economy. It would also be interesting if [34] had employed some sort of cardiovascular test, ideally the YYIRL 2.

Finally, it is possible to see that different training strategies can have similar outcomes in terms of affecting RSA performance, as plyometrics are common to both. Although sprints were the strongest predictor of RSA performance, the increased buildup of metabolites due to increases in power output should be accompanied by other training stimuli (like in [36]) that focus on increases in VO2max and buffer capacity to maximize RSA performance. Therefore, when implementing any sort of HIT work similar to that described above, training order (HIT or STR first) does not seem to cause significant differences. The same does not apply to sprint work, and endurance was mentioned along with sprinting, but could be performed on the same day as plyometrics.

\subsection{Study Limitations, Future Research, and Practical Applications}

One of the study limitations is the wide range of experimental designs included and the small number per dimension analysis. Therefore, generalizability cannot be performed with strong consistency. In line with the previous limitations, we suggest that future studies on CT in soccer (both with young and adult players) explore the physical and the physiological effects to confirm previous results.

The methodological quality of the included studies may also represent a risk in interpretation, namely contributing to a heterogeneity of results for the same dimension of analysis.

Regarding the acute effects of applying concurrent training methods in a real-world scenario, coaches and strength and conditioning practicians should pay more attention to volume, intensity, and proximity to failure according to how little the time between session players have to recover, thereby managing fatigue so that one training session does not affect the subsequent one. It seems important also to support athletes with proper nutrition between sessions so that performance is not limited by carbohydrate availability or the potential for muscle growth is not limited by protein intake. Finally, strength training can be used again as a means to potentiate the following training session, if not taken to failure. It also seems to be a good tool to utilize when teams travel abroad and suffer from jet lag, 
since it has the ability to change circadian rhythms. On the other hand, when used near sleeping hours, it could potentially affect sleep and, thus, recovery.

AMPK/SIRT1, ER stress, extended muscle damage, and fatigue (neural and peripheral) seem to be mechanisms via which each interference is modulated. Therefore:

(1) To reduce the impact of the interference mechanisms, strength training should be done 3-6 h before or after endurance training. If not possible, athletes should be supported with additional protein and carbohydrate ingestion between sessions.

(2) It seems that HIT or SIT training, such as the methods mentioned in [73], reduces AMPK activity and, therefore, reduces interference [21].

(3) The higher the contraction, such as sprinting and jump training, the more fatigue interferes, since this type of work should be done fully rested. Therefore, RSA $\left(6 \times 30 \mathrm{~m}\right.$ with $30^{\prime \prime}$ rest) is not a valid way to train sprinting. However, it is valid if complete rests are given between sets, so this is suggested to be done first, whether followed by strength or endurance training.

(4) Volume seems to be the most robust predictor of fatigue, whether in RT or ET. So, the volume of variables should be manipulated according to players' fitness levels and training experience.

(5) When training young players, interference does not seem to play a big role. Nevertheless, when training for technical improvements, fatigue can hinder learning, and so this type of work should be done first.

In addition to the information given earlier to coaches, their staff or practitioners and in order to recommend practical applications for $\mathrm{CT}$ programs, in future studies we recommend the following characteristics for resistance/strength training:

- 2 sessions per week of CT;

- begin the strength training with free weights or body weight exercises, without plyometrics;

- $\quad$ the progressive overload principle should be applied with the inclusion of plyometric exercises, but without achieving failure;

- $\quad$ switch between upper and lower limb exercises;

- $\quad 2-4$ sets with a range of $20-4$ repetitions, $50-85 \%$ of 1 RM per free weight and/or body weight exercise;

- $\quad$ 2-5 sets with a range of 3-10 repetitions per plyometric exercise;

- $\quad$ rest period should allow full recovery to avoid excessive fatigue.

\section{Conclusions}

Volume seems to be a significant predictor of interference, and endurance seems to be a limiting factor for strength (and not so much the other way around). Team staff must manipulate training variables according to players' age, training experience, fitness levels, rest time between sessions, and nutrition. It is difficult to implement the ideal scenario, but understanding the mechanisms behind interference can help practicians employ the best training program to maximize performance.

Author Contributions: J.R. and F.M.C. lead the project, ran the data search and methodological assessment, and wrote and revised the original manuscript; M.C., M.S., R.L. and R.O. revised the original manuscript; J.A. ran the data search and methodological assessment and wrote and revised the original manuscript; H.S. executed the methodological assessment, wrote and revised the original manuscript. All authors have read and agreed to the published version of the manuscript.

Funding: Filipe Manuel Clemente: This work is funded by Fundação para a Ciência e Tecnologia/ Ministério da Ciência, Tecnologia e Ensino Superior through national funds and when applicable cofunded EU funds under the project UIDB/EEA/50008/2020. Hugo Sarmento gratefully acknowledge the support of a Spanish government subproject Integration ways between qualitative and quantitative data, multiple case development, and synthesis review as main axis for an innovative future in physical activity and sports research [PGC2018-098742-B-C31] (Ministerio de Economía y Competitividad, Programa Estatal de Generación de Conocimiento y Fortalecimiento Científico y Tecnológico 
del Sistema $\mathrm{I}+\mathrm{D}+\mathrm{i})$, that is part of the coordinated project 'New approach of research in physical activity and sport from mixed methods perspective (NARPAS_MM) [SPGC201800X098742CV0]'. No other specific sources of funding were used to assist in the preparation of this article.

Acknowledgments: This study was done as part of a master thesis in sports training, Escola Superior de Desporto e Lazer, Instituto Politécnico de Viana do Castelo, Portugal.

Conflicts of Interest: The authors declare no conflict of interest.

\section{References}

1. De Souza, E.O.; Tricoli, V.; Roschel, H.; Brum, P.C.; Bacurau, A.V.N.; Ferreira, J.C.B.; Aoki, M.S.; Neves, M., Jr.; Aihara, A.Y.; Da Rocha Correa Fernandes, A.; et al. Molecular adaptations to concurrent training. Int. J. Sport. Med. 2013, 34, $207-213$. [CrossRef]

2. Murlasits, Z.; Kneffel, Z.; Thalib, L. The physiological effects of concurrent strength and endurance training sequence: A systematic review and meta-analysis. J. Sport. Sci. 2018, 36, 1212-1219. [CrossRef]

3. Nader, G.A. Concurrent strength and endurance training: From molecules to man. Med. Sci. Sport. Exerc. 2006, 38, 1965-1970. [CrossRef]

4. Di Salvo, V.; Baron, R.; Tschan, H.; Calderon Montero, F.J.; Bachl, N.; Pigozzi, F. Performance characteristics according to playing position in elite soccer. Int. J. Sport. Med. 2007, 28, 222-227. [CrossRef]

5. Stolen, T.; Chamari, K.; Castagna, C.; Wisloff, U. Physiology of soccer: An update. Sport. Med. 2005, 35, 501-536. [CrossRef] [PubMed]

6. Enright, K.; Morton, J.; Iga, J.; Drust, B. Implementing concurrent-training and nutritional strategies in professional football: A complex challenge for coaches and practitioners. Sci. Med. Footb. 2017, 1, 65-73. [CrossRef]

7. Kotzamanidis, C.; Chatzopoulos, D.; Michailidis, C.; Papaiakovou, G.; Dimitris, P. The Effect of a Combined High-Intensity Strength and Speed Training Program on the Running and Jumping Ability of Soccer Players. J. Strength Cond. Res. 2005, 19, 369-375.

8. Orendurff, M.S.; Walker, J.D.; Jovanovic, M.; Tulchin, K.L.; Levy, M.; Hoffmann, D.K. Intensity and duration of intermitt ent exercise and recovery during a soccer match. J. Strength Cond. Res. 2010, 24, 2683-2692. [CrossRef]

9. Bangsbo, J.; Mohr, M.; Krustrup, P. Physical and metabolic demands of training and match-play in the elite football player. J. Sport. Sci. 2006, 24, 665-674. [CrossRef] [PubMed]

10. Faude, O.; Koch, T.; Meyer, T. Straight sprinting is the most frequent action in goal situations in professional football. J. Sport. Sci. 2012, 30, 625-631. [CrossRef] [PubMed]

11. Fereday, K.; Hills, S.P.; Russell, M.; Smith, J.; Cunningham, D.J.; Shearer, D.; McNarry, M.; Kilduff, L.P. A comparison of rolling averages versus discrete time epochs for assessing the worst-case scenario locomotor demands of professional soccer match-play. J. Sci. Med. Sport 2020, 23, 764-769. [CrossRef] [PubMed]

12. Wing, C.E.; Turner, A.N.; Bishop, C.J. Importance of strength and power on key performance indicators in elite youth soccer. J. Strength Cond. Res. 2020, 34, 2006-2014. [CrossRef] [PubMed]

13. Harrison, C.B.; Gill, N.D.; Kinugasa, T.; Kilding, A.E. Development of aerobic fitness in young team sport athletes. Sport. Med. 2015, 45, 969-983. [CrossRef]

14. Loturco, I.; Kobal, R.; Kitamura, K.; Cal Abad, C.C.; Faust, B.; Almeida, L.; Pereira, L.A. Mixed training methods: Effects of combining resisted sprints or plyometrics with optimum power loads on sprint and agility performance in professional soccer players. Front. Physiol. 2017, 8, 1034. [CrossRef] [PubMed]

15. Brachman, A.; Kamieniarz, A.; Michalska, J.; Pawłowski, M.; Słomka, K.J.; Juras, G. Balance training programs in athletesA systematic review. J. Hum. Kinet. 2017, 58, 45-64. [CrossRef] [PubMed]

16. Suchomel, T.J.; Nimphius, S.; Stone, M.H. The importance of muscular strength in athletic performance. Sport. Med. 2016, 46, 1419-1449. [CrossRef] [PubMed]

17. Clemente, F.M. The threats of small-sided soccer games. Strength Cond. J. 2020, 42, 100-105. [CrossRef]

18. Støren, Ø.; Helgerud, J.; Støa, E.M.; Hoff, J. Maximal strength training improves running economy in distance runners. Med. Sci. Sport. Exerc. 2008, 40, 1087-1092. [CrossRef]

19. Ross, A.; Gill, N.; Cronin, J. Match analysis and player characteristics in rugby sevens. Sport. Med. 2014, 44, 357-367. [CrossRef]

20. Wilson, J.M.; Marin, P.J.; Rhea, M.R.; Wilson, S.M.C.; Loenneke, J.P.; Anderson, J.C. Concurrent training: A meta-analysis examining interference of aerobic and resistance exercises. J. Strength Cond. Res. 2012, 26, 2293-2307. [CrossRef]

21. Methenitis, S. A Brief review on concurrent training: From laboratory to the field. Sports 2018, 6, 127. [CrossRef]

22. Izquierdo, M.; García, J. Strategies to optimize concurrent training of strength and aerobic fitness for rowing and canoeing strategies to optimize concurrent training of strength and aerobic fitness for rowing and canoeing. Sport. Med. 2011, 41, 329-343.

23. Balsalobre-Fernández, C.; Santos-Concejero, J.; Grivas, G.V. Effects of strength training on running economy in highly trained runners: A systematic review with meta-analysis of controlled trials. J. Strength Cond. Res. 2016, 30, 2361-2368. [CrossRef]

24. Baar, K. Using molecular biology to maximize concurrent training. Sport. Med. 2014, 44, 117-125. [CrossRef]

25. Green, S.; Higgins, J. Cochrane Handbook for Systematic Reviews of Interventions; John Wiley \& Sons: Hoboken, NJ, USA, 2005. 
26. Moher, D.; Liberati, A.; Tetzlaff, J.; Altman, D.G. Preferred reporting items for systematic reviews and meta-analyses: The PRISMA statement. PLoS Med. 2009, 6, e1000097. [CrossRef]

27. Collaboration, C. Data Extraction Template for Included Studies. Available online: https://cccrg.cochrane.org/sites/cccrg cochrane.org/files/public/uploads/det_2015_revised_final_june_20_2016_nov_29_revised.doc (accessed on 2 January 2021).

28. Impellizzeri, F.M.; Marcora, S.M.; Coutts, A.J. Internal and external training load: 15 years on. Int. J. Sport. Physiol. Perform. 2019, 14, 270-273. [CrossRef] [PubMed]

29. Sterne, J.A.C.; Savović, J.; Page, M.J.; Elbers, R.G.; Blencowe, N.S.; Boutron, I.; Cates, C.J.; Cheng, H.-Y.; Corbett, M.S.; Eldridge, S.M.; et al. RoB 2: A revised tool for assessing risk of bias in randomised trials. BMJ 2019, 366, 14898. [CrossRef] [PubMed]

30. Sterne, J.A.; Hernán, M.A.; Reeves, B.C.; Savović, J.; Berkman, N.D.; Viswanathan, M.; Henry, D.; Altman, D.G.; Ansari, M.T.; Boutron, I.; et al. ROBINS-I: A tool for assessing risk of bias in non-randomised studies of interventions. BMJ 2016, 355 , i4919. [CrossRef] [PubMed]

31. Sparkes, W.; Turner, A.N.; Weston, M.; Russell, M.; Johnston, M.J.; Kilduff, L.P. The effect of training order on neuromuscular, endocrine and mood response to small-sided games and resistance training sessions over a 24-h period. J. Sci. Med. Sport 2020, 23, 866-871. [CrossRef] [PubMed]

32. Enright, K.; Morton, J.; John, I.G.A.; Drust, B. Hormonal responses during two different concurrent-training trials in youth elite soccer players: Does changing the organization of training impact the hormonal response to concurrent exercise? J. Sport. Med. Phys. Fit. 2018, 58, 699-706.

33. Enright, K.; Morton, J.; Iga, J.; Drust, B. The effect of concurrent training organisation in youth elite soccer players. Eur. J. Appl. Physiol. 2015, 115, 2367-2381. [CrossRef] [PubMed]

34. Kargarfard, M.; Tajvand, S.; Rabbani, A.; Clemente, F.M.; Jalilvand, F. Effects of combined plyometric and speed training on change of direction, linear speed, and repeated sprint ability in young soccer players: A pilot study. Kinesiology 2020, 52, 85-93. [CrossRef]

35. Makhlouf, I.; Castagna, C.; Manzi, V.; Laurencelle, L.; Behm, D.G.; Chaouachi, A. Effect of sequencing strength and endurance training in young male soccer players. J. Strength Cond. Res. 2016, 30, 841-850. [CrossRef] [PubMed]

36. McGawley, K.; Andersson, P.I. The order of concurrent training does not affect soccer-related performance adaptations. Int. J. Sport. Med. 2013, 34, 983-990. [CrossRef]

37. Cook, C.J.; Kilduff, L.P.; Crewther, B.T.; Beaven, M.; West, D.J. Morning based strength training improves afternoon physical performance in rugby union players. J. Sci. Med. Sport 2014, 17, 317-321. [CrossRef] [PubMed]

38. Silva, P.; Dos Santos, E.; Grishin, M.; Rocha, J.M. Validity of heart rate-based indices to measure training load and intensity in elite football players. J. Strength Cond. Res. 2018, 32, 2340-2347. [CrossRef]

39. Schoenfeld, B.J.; Ogborn, D.; Krieger, J.W. Dose-response relationship between weekly resistance training volume and increases in muscle mass: A systematic review and meta-analysis. J. Sport. Sci. 2017, 35, 1073-1082. [CrossRef]

40. Eklund, D.; Pulverenti, T.; Bankers, S.; Avela, J.; Newton, R.; Schumann, M.; Häkkinen, K. Neuromuscular adaptations to different modes of combined strength and endurance training. Int. J. Sport. Med. 2015, 36, 120-129. [CrossRef]

41. Machek, S.B.; Hwang, P.S.; Cardaci, T.D.; Wilburn, D.T.; Bagley, J.R.; Blake, D.T.; Galpin, A.J.; Willoughby, D.S. Myosin heavy chain composition, creatine analogues, and the relationship of muscle creatine content and fast-twitch proportion to Wilks coefficient in powerlifters. J. Strength Cond. Res. 2020, 34, 3022-3030. [CrossRef]

42. Wilson, G.J. The specificity of strength training: The effect of posture. Eur. J. Appl. Physiol. Occup. Physiol. 1996, 73, 346-352. [CrossRef]

43. Harris, G.R.; Stone, M.H.; O’Bryant, H.S.; Proulx, C.M.; Johnson, R.L. Short-term performance effects of high power, high force, or combined weight-training methods. J. Strength Cond. Res. 2000, 14, 14-20.

44. Young, W.B. Transfer of strength and power training to sports performance. Int. J. Sport. Physiol. Perform. 2006, 1, 74-83. [CrossRef]

45. Kumagai, K.; Abe, T.; Brechue, W.F.; Ryushi, T.; Takano, S.; Mizuno, M. Sprint performance is related to muscle fascicle length in male 100-m sprinters. J. Appl. Physiol. 2000, 88, 811-816. [CrossRef]

46. Musch, J.; Grondin, S. Unequal competition as an impediment to personal development: A review of the relative age effect in sport. Dev. Rev. 2001, 21, 147-167. [CrossRef]

47. Lloyd, R.S.; Oliver, J.L. The youth physical development model: A new approach to long-term athletic development. Strength Cond. J. 2012, 34, 61-72. [CrossRef]

48. Markovic, G.; Mikulic, P. Neuro-musculoskeletal and performance adaptations to lower-extremity plyometric training. Sport. Med. 2010, 40, 859-895. [CrossRef]

49. National Strength and Conditioning Association. Developing Agility and Quickness; Dawes, J., Ed.; Human Kinetics: Champaign, IL, USA, 2018; ISBN 9781492569510.

50. Spurrs, R.W.; Murphy, A.J.; Watsford, M.L. The effect of plyometric training on distance running performance. Eur. J. Appl. Physiol. 2003, 89, 1-7. [CrossRef] [PubMed]

51. Da Silva, J.F.; Guglielmo, L.G.A.; Bishop, D. Relationship between different measures of aerobic fitness and repeated-sprint ability in elite soccer players. J. Strength Cond. Res. 2010, 24, 2115-2121. [CrossRef] 
52. Crewther, B.T.; Cook, C.; Cardinale, M.; Weatherby, R.P.; Lowe, T. Two emerging concepts for elite athletes neuromuscular system and the dose-response training role of these endogenous hormones. Sport. Med. 2011, 41, 103-123. [CrossRef]

53. Lorenz, D. Postactivation potentiation: An introduction. Int. J. Sports Phys. Ther. 2011, 6, 234-240.

54. Stone, M.H.; Sands, W.A.; Pierce, K.C.; Ramsey, M.W.; Haff, G.G. Power and power potentiation among strength-power athletes: Preliminary study. Int. J. Sport. Physiol. Perform. 2008, 3, 55-67. [CrossRef]

55. Aarts, H.; Van Honk, J. Testosterone and unconscious positive priming increase human motivation separately. Neuroreport 2009, 20, 1300-1303. [CrossRef] [PubMed]

56. Crewther, B.T.; Cook, C.J.; Gaviglio, C.M.; Kilduff, L.P.; Drawer, S. Baseline strength can influence the ability of salivary free testosterone to predict squat and sprinting performance. J. Strength Cond. Res. 2012, 26, 261-268. [CrossRef]

57. Jeukendrup, A.E. Carbohydrate intake during exercise and performance. Nutrition 2004, 20, 669-677. [CrossRef] [PubMed]

58. Martinez, D. From the field-directed topic: The use of reactive strength index, reactive strength infex modified, and flight time: Contraction time as monitoring tools. J. Aust. Strength Cond. 2006, 24, 37-41.

59. Coffey, V.G.; Pilegaard, H.; Garnham, A.P.; O’Brien, B.J.; Hawley, J.A. Consecutive bouts of diverse contractile activity alter acute responses in human skeletal muscle. J. Appl. Physiol. 2009, 106, 1187-1197. [CrossRef] [PubMed]

60. Sabag, A.; Najafi, A.; Michael, S.; Esgin, T.; Halaki, M.; Hackett, D. The compatibility of concurrent high intensity interval training and resistance training for muscular strength and hypertrophy: A systematic review and meta-analysis. J. Sport. Sci. 2018, 36, 2472-2483. [CrossRef]

61. Perez-Schindler, J.; Hamilton, D.L.; Moore, D.R.; Baar, K.; Philp, A. Nutritional strategies to support concurrent training. Eur. J. Sport Sci. 2015, 15, 41-52. [CrossRef] [PubMed]

62. Häkkinen, K.; Alen, M.; Kraemer, W.J.; Gorostiaga, E.; Izquierdo, M.; Rusko, H.; Mikkola, J.; Häkkinen, A.; Valkeinen, H.; Kaarakainen, E.; et al. Neuromuscular adaptations during concurrent strength and endurance training versus strength training. Eur. J. Appl. Physiol. 2003, 89, 42-52. [CrossRef] [PubMed]

63. Reggiani, C.; Schiaffino, S. Muscle hypertrophy and muscle strength: Dependent or independent variables? A provocative review. Eur. J. Transl. Myol. 2020, 30, 9311. [CrossRef]

64. Wilson, J.M.; Loenneke, J.P.; Jo, E.; Wilson, G.J.; Zourdos, M.C.; Kim, J.-S. The effects of endurance, strength, and power training on muscle fiber type shifting. J. Strength Cond. Res. 2012, 26, 1724-1729. [CrossRef]

65. Impellizzeri, F.M.; Marcora, S.M.; Castagna, C.; Reilly, T.; Sassi, A.; Iaia, F.M.; Rampinini, E. Physiological and performance effects of generic versus specific aerobic training in soccer players. Int. J. Sport. Med. 2006, 27, 483-492. [CrossRef] [PubMed]

66. Hakkinen, K.; Alen, M.; Kallinen, M.; Newton, R.U.; Kraemer, W.J. Neuromuscular adaptation during prolonged strength training, detraining and re-strength-training in middle-aged and elderly people. Eur. J. Appl. Physiol. 2000, 83, 51-62. [CrossRef] [PubMed]

67. Alén, M.; Häkkinen, K.; Komi, P.V. Changes in neuromuscular performance and muscle fiber characteristics of elite power athletes self-administering androgenic and anabolic steroids. Acta Physiol. Scand. 1984, 122, 535-544. [CrossRef] [PubMed]

68. Falk, B.; Dotan, R. Child-adult differences in the recovery from high-intensity exercise. Exerc. Sport Sci. Rev. 2006, 34, 107-112. [CrossRef] [PubMed]

69. Ratel, S.; Duché, P.; Williams, C.A. Muscle fatigue during high-intensity exercise in children. Sport. Med. 2006, 36, 1031-1065. [CrossRef] [PubMed]

70. Hammami, M.; Negra, Y.; Shephard, R.J.; Chelly, M.S. Effects of leg contrast strength training on sprint, agility and repeated change of direction performance in male soccer players. J. Sport. Med. Phys. Fit. 2017, 57, 1424-1431.

71. Tabata, I.; Nishimura, K.; Kouzaki, M.; Hirai, Y.; Ogita, F.; Miyachi, M.; Yamamoto, K. Effects of moderate-intensity endurance and high-intensity intermittent training on anaerobic capacity and $\mathrm{VO}(2 \mathrm{max})$. Med. Sci. Sport. Exerc. 1996, 28, 1327-1330. [CrossRef]

72. Bangsbo, J.; Iaia, F.M.; Krustrup, P. The Yo-Yo intermittent recovery test: A useful tool for evaluation of physical performance in intermittent sports. Sport. Med. 2008, 38, 37-51. [CrossRef]

73. Baker, D. Recent trends in high-intensity aerobic training for field sports. Prof. Strength Cond. 2011, 22, 3-8. 